\title{
Analysis of the origin of water, carbon monoxide, and carbon dioxide in the Uranus atmosphere
}

\author{
L. M. Lara ${ }^{1}$, R. Rodrigo ${ }^{2}$, R. Moreno ${ }^{3}$, and M. Lampón ${ }^{1}$ \\ ${ }^{1}$ Instituto de Astrofísica de Andalucía - CSIC, c/ Glorieta de la Astronomía s/n, 18008 Granada, Spain \\ e-mail: lara@iaa.csic.es \\ 2 International Space Science Institute, Hallerstrasse 6, 3012 Bern, Switzerland, and Centro de Astrobiologia (INTA-CSIC), \\ European Space Agency (ESA), European Space Astronomy Centre (ESAC), Camino Bajo del Castillo s/n, Urb. Villafranca \\ del Castillo, 28692 Villanueva de la Cañada, Madrid, Spain \\ ${ }^{3}$ LESIA, Observatoire de Paris - Meudon, 92195 Meudon Principal Cedex, France
}

Received 18 October 2017 / Accepted 17 November 2018

\begin{abstract}
Context. We present here an analysis of the potential sources of oxygen species in the Uranus atmosphere.

Aims. Our aim is to explain the current measurements of $\mathrm{H}_{2} \mathrm{O}, \mathrm{CO}$, and $\mathrm{CO}_{2}$ in the Uranus atmosphere, which would allow us to constrain the influx of oxygen-bearing species and its origin in this planet.

Methods. We used a time-dependent photochemical model of the Uranus atmosphere to ascertain the origin of $\mathrm{H}_{2} \mathrm{O}, \mathrm{CO}$, and $\mathrm{CO}_{2}$. We thoroughly investigated the evolution of material delivered by a cometary impact, together with a combined source, i.e. cometary impact and a steady source of oxygen species from micrometeoroid ablation.

Results. We find that an impactor in the size range $\sim 1.2-3.5 \mathrm{~km}$ hitting the planet between 450 and 822 yr ago could have delivered the $\mathrm{CO}$ currently seen in the Uranus stratosphere. Given the current set of observations, an oxygen-bearing species supply from ice grain ablation cannot be ruled out. Our study also indicates that a cometary impact cannot be the only source for rendering the observed abundances of $\mathrm{H}_{2} \mathrm{O}$ and $\mathrm{CO}_{2}$. The scenarios in which $\mathrm{CO}$ originates by a cometary impact and $\mathrm{H}_{2} \mathrm{O}$ and $\mathrm{CO}_{2}$ result from ice grain sublimation can explain both the space telescope and ground-based data for $\mathrm{H}_{2} \mathrm{O}, \mathrm{CO}$, and $\mathrm{CO}_{2}$. Similarly, a steady influx of water, carbon monoxide, and carbon dioxide, and a cometary impact delivering carbon monoxide give rise to abundances matching the observations. The time evolution of $\mathrm{HCN}$ also delivered by a cometary impact (as 1\% of the CO in mass), when discarding chemical recycling of $\mathrm{HCN}$ once it is lost by photolysis and condensation, produces a very low stratospheric abundance which could be likely non-detectable. Consideration of $\mathrm{N}_{2}$-initiated chemistry could represent a source of $\mathrm{HCN}$ allowing for a likely observable stratospheric mixing ratio.

Conclusions. Our modelling strongly indicates that water in the Uranus atmosphere likely originates from micrometeroid ablation, whereas its cometary origin can be discarded with a very high level of confidence. Also, we cannot firmly constrain the origin of the detected carbon monoxide on Uranus as a cometary impact, ice grain ablation, or a combined source due to both processes can give rise to the atmospheric mixing ratio measured with the Herschel Space Observatory. To establish the origin of oxygen species in the Uranus atmosphere, observations have to allow the retrieval of vertical profiles or $\mathrm{H}_{2} \mathrm{O}, \mathrm{CO}$, and $\mathrm{CO}_{2}$. Measurements in narrow pressure ranges, i.e. basically one pressure level, can be reproduced by different models because it is not possible to break this degeneracy about these three oxygen species in the Uranian atmosphere.
\end{abstract}

Key words. planets and satellites: atmospheres - planets and satellites: gaseous planets - planets and satellites: individual: Uranus planets and satellites: composition

\section{Introduction}

The presence of water vapour in the stratosphere of the outer planets, as established by the Infrared Space Observatory (ISO), has raised the question of the origin of external oxygen in these reducing environments. While the gross similarity of the $\mathrm{H}_{2} \mathrm{O}$ fluxes into the four giant planets (Feuchtgruber et al. 1997) might have been taken as evidence that micrometeorite ablation is the dominant source, recent observations, especially using the Herschel Space Observatory and Spitzer Space Telescope (hereafter Herschel and Spitzer), have revealed a different picture. These datasets outline the likely role of recent cometary impacts in delivering oxygen species to the atmospheres of the outer planets.

The current abundance of $\mathrm{H}_{2} \mathrm{O}$ and $\mathrm{CO}$ in Jupiter can be explained by the Shoemaker-Levy 9 impact (Lellouch et al.
1997, 2002; Cavalié et al. 2013), whereas for Saturn and Neptune the CO observations point to three potential sources: (i) micrometeoroid ablation, (ii) cometary impacts, and (iii) local sources (satellites, rings; Feuchtgruber et al. 1997; Moses et al. 2000b; Cavalié et al. 2009, 2010; Lellouch et al. 2005, 2010; Fletcher et al. 2012). The case of oxygen species in Titan's atmosphere reflects a complex scenario where the Enceladus source seems to be variable with time (Moreno et al. 2012; Lara et al. 2014).

The abundance of $\mathrm{CO}$ in the Uranus stratosphere (200100 mbar) is only constrained by an upper limit of $2.1 \times 10^{-9}$ (Teanby \& Irwin 2013) constant with altitude (or $9.4 \times 10^{-9}$ for a stratosphere-only profile). Cavalié et al. (2014) used Herschel data to set up a stratospheric $\mathrm{CO}$ mixing ratio of $7.1-9 \times 10^{-9}$. Diffusion models (i.e. discarding photochemical and condensation processes) by Cavalié et al. (2014) studied whether an internal source of $\mathrm{CO}$, a cometary impact delivering this species 
at 0.1 mbar, or a steady $\mathrm{CO}$ influx could explain the currently available observations. The least favoured scenario by these authors is the internal source. Although the core of the line observed by Herschel can be fitted, the needed $\mathrm{CO}$ mixing ratio $\left(q_{\mathrm{CO}}\right)$ in the deep atmosphere that diffuses upwards to match the Herschel-HIFI data is $\sim 10$ times higher than the upper limit set by Herschel-SPIRE (Teanby \& Irwin 2013). Therefore, the results of their investigation indicate that current observations cannot help to discriminate between a cometary impact or a steady source of $\mathrm{CO}$ being responsible for its currently measured abundance in the Uranus stratosphere. This leaves open the possibility that a combination of the two processes could give rise to the measured CO.

Recently, Moses \& Poppe (2017; MP17) have developed sophisticated micrometeoroid ablation models, both for water ice grains and refractory material entering the atmospheres of Jupiter, Saturn, Neptune, and Uranus. These ablation profiles are used as oxygen sources in the frame of a photochemical model which couples hydrocarbon and oxygen chemistry. Their conclusion regarding Uranus is that the $\mathrm{H}_{2} \mathrm{O}$ abundance measured by ISO (Feuchtgruber et al. 1997), and the $\mathrm{CO}_{2}$ obtained with the Spitzer infrared spectrometer (Orton et al. 2014b) and the CO with Herschel (Cavalié et al. 2014) can be reproduced for the following integrated ablation fluxes: $1.2 \times 10^{5} \mathrm{~cm}^{-2} \mathrm{~s}^{-1}$, $3.0 \times 10^{3} \mathrm{~cm}^{-2} \mathrm{~s}^{-1}$, and $2.7 \times 10^{5} \mathrm{~cm}^{-2} \mathrm{~s}^{-1}$, respectively (total oxygen influx of $4 \times 10^{5} \mathrm{~cm}^{-2} \mathrm{~s}^{-1}$ ), these values not being very dependent on the assumed eddy diffusion coefficient within the range explored by Orton et al. (2014b).

In this work (TW18), by means of a time-dependent photochemical model, we explore in more detail the scenario of a cometary impact, as well as a combination of cometary impact and ice grain ablation as likely sources of oxygen in the Uranus atmosphere. By analysing the event of a cometary impact, we aim to address whether this phenomenon, which seems probable on the other giant planets, could also have taken place on Uranus some time ago such that the oxygen species currently seen on Uranus originated from a single event. We also explore a combined source (i.e. cometary impact and steady source of ice grain ablation) as precursor of $\mathrm{H}_{2} \mathrm{O}, \mathrm{CO}$, and $\mathrm{CO}_{2}$ on this planet.

\section{Model description}

The number density $n$ at altitude $z$ for every constituent $i$ at time $t$ is solved by means of the usual continuity equations in planeparallel geometry:

$\frac{\partial n_{i}}{\partial t}=P_{i}-n_{i} l_{i}-\frac{\partial \Phi_{i}}{\partial z}$

where $\Phi_{i}$ can be expressed as

$\Phi_{i}=-n_{i} D_{i}\left(\frac{1}{n_{i}} \frac{\partial n_{i}}{\partial z}+\frac{1+\alpha_{i}}{T} \frac{\partial T}{\partial z}+\frac{1}{H_{i}}\right)-n_{i} K\left(\frac{1}{n_{i}} \frac{\partial n_{i}}{\partial z}+\frac{1}{T} \frac{\partial T}{\partial z}+\frac{1}{H}\right)$.

The variables $n_{i}, P_{i}$, and $l_{i}$ are the number density, volumic production rate, and volumic specific loss rate, and the altitude runs from -75 to $2800 \mathrm{~km}$, with an altitude bin size of $5 \mathrm{~km}$. The pressure levels covered in the model range from 5.3 bar to $1.05 \times 10^{-7} \mathrm{mbar}$, and the $0 \mathrm{~km}$ altitude level is set at 1 bar.

The parameter $D_{i}$ is the molecular diffusion coefficient, $T$ is the temperature, $H_{i}$ and $H$ are the individual and atmospheric scale heights, respectively, $K(z)$ is the eddy diffusion coefficient, and $\alpha_{i}$ is the thermal diffusion coefficient.

The equations are solved for $\mathrm{H}, \mathrm{He}$, methane $\left(\mathrm{CH}_{4}\right)$, methyl radical $\left(\mathrm{CH}_{3}\right)$, acetylene $\left(\mathrm{C}_{2} \mathrm{H}_{2}\right)$, ethylene $\left(\mathrm{C}_{2} \mathrm{H}_{4}\right)$, ethane $\left(\mathrm{C}_{2} \mathrm{H}_{6}\right)$, methyl acetylene $\left(\mathrm{CH}_{3} \mathrm{C}_{2} \mathrm{H}\right)$, propene $\left(\mathrm{C}_{3} \mathrm{H}_{6}\right)$, propane $\left(\mathrm{C}_{3} \mathrm{H}_{8}\right), \mathrm{C}_{3} \mathrm{H}_{2}, \mathrm{C}_{3} \mathrm{H}_{5}, \mathrm{C}_{3} \mathrm{H}_{7}$, diacetylene $\left(\mathrm{C}_{4} \mathrm{H}_{2}\right), \mathrm{CH}, \mathrm{C}_{2}, \mathrm{C}_{4} \mathrm{H}$, $\mathrm{C}_{3} \mathrm{H}_{5}, \mathrm{C}_{2} \mathrm{H},{ }^{1} \mathrm{CH}_{2},{ }^{3} \mathrm{CH}_{2}, \mathrm{C}_{2} \mathrm{H}_{3}, \mathrm{C}_{2} \mathrm{H}_{5}, \mathrm{C}_{4} \mathrm{H}_{2}^{*}, \mathrm{C}_{4} \mathrm{H}_{3}$, water $\left(\mathrm{H}_{2} \mathrm{O}\right)$, carbon monoxide $(\mathrm{CO})$, carbon dioxide $\left(\mathrm{CO}_{2}\right)$, methanol $\left(\mathrm{CH}_{3} \mathrm{OH}\right), \mathrm{CH}_{2} \mathrm{OH}, \mathrm{CH}_{3} \mathrm{O}, \mathrm{HCCO}, \mathrm{CH}_{3} \mathrm{CO}, \mathrm{C}_{2} \mathrm{H}_{4} \mathrm{OH}$, molecular oxygen $\left(\mathrm{O}_{2}\right), \mathrm{CH}_{2} \mathrm{CO}, \mathrm{CH}_{3} \mathrm{CHO} \mathrm{O}\left({ }^{3} \mathrm{P}\right)$, formyl $(\mathrm{HCO})$, formaldehyde $\left(\mathrm{H}_{2} \mathrm{CO}\right)$, hydroxyl $(\mathrm{OH}), \mathrm{O}\left({ }^{1} \mathrm{~S}\right), \mathrm{O}\left({ }^{1} \mathrm{D}\right), \mathrm{CH}_{3} \mathrm{O}$, and $\mathrm{CH}_{3} \mathrm{CO}$.

We use a fully implicit finite difference scheme (unconditionally stable) with a variable time step, $\Delta t$, to accommodate the wide range of characteristic lifetimes (i.e. turbulent transport, molecular diffusion, and chemical) for every species. The abundance of every species at every atmospheric level is determined by the balance of photochemical and transport processes. If the computed number density $n_{i}$ due to these processes is higher than the value allowed by the saturation law at the prevailing pressure and temperature at that level $n_{\text {is }}$, i.e. $\frac{n_{i}}{n_{i s}}=S>1$, then a condensation term is added to the photochemical loss. Lavvas et al. (2008a,b) recommend

$l_{s i}=A\left(1-\frac{1}{S_{i}}\right) \frac{\exp \left(-0.5 / \ln ^{2}\left(S_{i}+1\right)\right)}{\ln ^{2}\left(S_{i}+1\right)}$.

Here $A$ is a constant in the range $(0.1-1) \times 10^{-7} \mathrm{~s}^{-1}$ as in Lavvas et al. (2008b) and Krasnopolsky (2009). The above expression provides increasing condensation loss rates with increasing saturation ratios $S_{i}$. By varying the $A$ values within the range given above, the resulting mixing ratio profiles below the condensation levels are noticeably affected, whereas at the pressure region where $\mathrm{H}_{2} \mathrm{O}$ and $\mathrm{CO}_{2}$ observations are available the resulting profiles differ only by $3-4 \%$. Thus, we set $A=1 \times 10^{-7} \mathrm{~s}^{-1}$, as Lavvas et al. (2008b) considered for Titan's atmosphere.

At 5.3 bar, the lower boundary of our model computations, the condition is set as maximum downward velocity for every species except $\mathrm{He}$ and $\mathrm{CO}$ having constant mixing ratio $\left(q_{\mathrm{CO}}=\right.$ $5.0 \times 10^{-10}$ as in Moses \& Poppe 2017). For $\mathrm{CH}_{4}$, the mixing ratio is set to $1.0 \times 10^{-5}$, which corresponds to its stratospheric value (Orton et al. 2014a; Lellouch et al. 2015). We note that we discard its condensation as it is unimportant for the study of the water, carbon monoxide, and dioxide stratospheric abundances.

At the upper boundary of the model placed at $1.05 \times$ $10^{-7}$ mbar (or $2800 \mathrm{~km}$ above the $0 \mathrm{~km}$ altitude level placed at 1 bar), every species is in diffusive equilibrium (i.e. zero flux). Atomic hydrogen is injected in the atmosphere at a rate of $4 \times 10^{7} \mathrm{~cm}^{-2} \mathrm{~s}^{-1}$ (Moses et al. 2005) due to the photodissociation of $\mathrm{H}_{2}$ taking place above $1.05 \times 10^{-7} \mathrm{mbar}$.

Our models are run for $K(z)=5000 \mathrm{~cm}^{2} \mathrm{~s}^{-1}$, as in Moses \& Poppe (2017), for a better comparison of our results with theirs. Since our aim is to determine whether a cometary impact could have been responsible for the $\mathrm{CO}$ abundance observed today, once the size $D$ of the impactor and the time of the event $t_{\text {impact }}$ are constrained, we will study how $t_{\text {impact }}$ varies as a function of $K(z)$, for one particular $D$, to check whether it is compatible with estimates by Zahnle et al. (2003). We assume that the cometary material is delivered at a pressure level of $0.1 \mathrm{mbar}$ (Lellouch et al. 1997, 2002). Model results for $K(z)=1200 \mathrm{~cm}^{2} \mathrm{~s}^{-1}$ (Cavalié et al. 2014) will be obtained and conclusions will be drawn.

The model, which was originally derived from González et al. (2011), has been adapted to the Uranus atmosphere by 


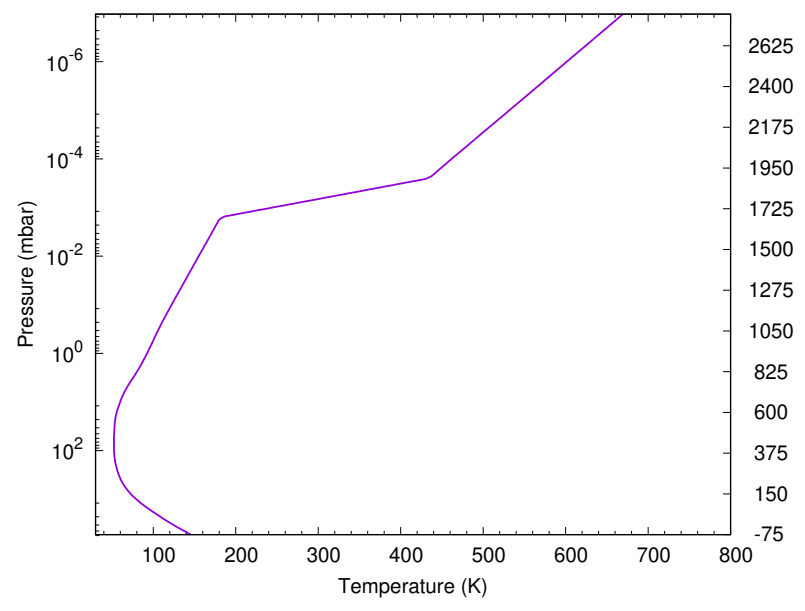

Fig. 1. Thermal vertical profile of the Uranus atmosphere from Orton et al. (2014a).

Table 1. Hydrocarbon column abundances at $p<10$ mbar versus Spitzer observational results (Orton et al. 2014b).

\begin{tabular}{lcc}
\hline \hline Species & $\begin{array}{c}\text { Spitzer } \\
\left(\mathrm{cm}^{-2}\right)\end{array}$ & $\begin{array}{c}\text { This model } \\
\left(\mathrm{cm}^{-2}\right)\end{array}$ \\
\hline $\mathrm{CH}_{4}$ & $4.5 \pm 1.1 \times 10^{19}$ & $4.3 \times 10^{19}$ \\
$\mathrm{C}_{2} \mathrm{H}_{2}$ & $6.2 \pm 1.1 \times 10^{16}$ & $4.8 \times 10^{16}$ \\
$\mathrm{C}_{2} \mathrm{H}_{6}$ & $3.1 \pm 0.4 \times 10^{16}$ & $1.7 \times 10^{17}$ \\
$\mathrm{CH}_{3} \mathrm{C}_{2} \mathrm{H}$ & $8.6 \pm 1.6 \times 10^{13}$ & $4.1 \times 10^{11}$ \\
$\mathrm{C}_{4} \mathrm{H}_{2}$ & $1.8 \pm 0.3 \times 10^{13}$ & $9.3 \times 10^{11}$ \\
$\mathrm{CH}_{3}$ & $<3.3 \times 10^{12}$ & $4.4 \times 10^{12}$ \\
\hline
\end{tabular}

Notes. The derived column abundances of stratospheric species result from the nominal model in Orton et al. (2014b) and the uncertainties represent the spectral fitting uncertainty and the uncertainty derived from the range of acceptable methane mixing ratios and eddy diffusion coefficients.

using the pressure-temperature profile in Orton et al. (2014a) shown in Fig. 1, considering a chemical network both for hydrocarbons and oxygen species derived from Moses et al. (2000a,b, 2005) and references therein. Some of the hydrocarbon reaction rates are updated as in Orton et al. (2014b) to allow for a more efficient recycling of $\mathrm{C}_{2} \mathrm{H}_{2}$, and we have also considered ethylene absorption cross sections measured at low temperatures by $\mathrm{Wu}$ et al. (2004). Comparison of the column densities that best match the measurements by Spitzer (Orton et al. 2014b) and the values computed in this work can be seen in Table 1. For this comparison, we have set $q_{\mathrm{CH}_{4}}$ at the lower boundary of the model to $1.6 \times 10^{-5}$, as in Orton et al. (2014b). On the other hand, the analysis of the oxygen species origin and abundance uses $q_{\mathrm{CH}_{4}}=1.0 \times 10^{-5}$, as in Moses \& Poppe (2017), for a more consistent comparison between our results and theirs. We note that this work does not focus on reproducing the hydrocarbon measurements, whose abundances derive from the chemistry initiated by methane photodissociation.

The hydrocarbon column densities obtained in this work vary by $<1 \%$ when the considered total oxygen steady influx is within the results given in Moses \& Poppe (2017) (i.e. $8.9_{-6.1}^{+19} \times$ $10^{4} \mathrm{~cm}^{-2} \mathrm{~s}^{-1}$ oxygen atoms). This almost negligible difference is due to the strong depletion of hydrocarbons at $p<0.5 \mathrm{mbar}$, whereas ice grain ablation produces oxygen species at those pressure levels. Therefore, oxygen species and hydrocarbons are chemically decoupled. On the other hand, the column abundances of species listed in Table 1 show variations of $\leq 13 \%$ for the different cometary impact cases analysed in this work. As the $\mathrm{CO}$ delivered by the impactor at $p \leq 0.1 \mathrm{mbar}$ is downward transported, it reaches atmospheric regions at the 0.2-1.0 mbar pressure level where methane abundance has not been considerably reduced by diffusive separation. Hence, some chemical interaction between hydrocarbons and oxygen species develops. Nevertheless, these variations are within the error bars derived from Spitzer data and photochemical modelling.

The oxygen species chemical network considered in this work is given in Appendix A. It derives from Moses et al. (2000b). The $\mathrm{H}_{2} \mathrm{O}, \mathrm{CO}$, and $\mathrm{CO}_{2}$ abundance profiles are very little dependent on this network and on the hydrocarbon chemical reactions (see above), their vertical mixing ratio profiles being mostly determined by the influx of oxygen (steady or single event such as a cometary impact in the past) and the diffussion processes. This is so because low values of $K(z)$ like those in the Uranus atmosphere result in methane homopause located at $\sim 0.3-0.8$ mbar; $\mathrm{H}_{2} \mathrm{O}$ and $\mathrm{CO}_{2}$ condense at relatively high atmospheric levels, and $\mathrm{CO}$ is highly stable, thus hydrocarbons and oxygen species turn out to be located in different stratospheric layers, and thus oxygen-carbon coupling chemistry can be considered unimportant.

\section{Radiative transfer model}

The Herschel $\mathrm{CO}$ spectra have been modelled with a line-by-line radiative transfer model, which takes into account the spherical geometry and broadening due to planetary rotation, developed for Jupiter (Moreno et al. 2001) and also used for Neptune (Moreno et al. 2017). The CO opacity parameters were taken from the Jet Propulsion Laboratory molecular line catalogue (Pickett et al. 1998); the collision-induced absorption opacity due to the main compounds of the Uranus atmosphere $\left(\mathrm{H}_{2}-\right.$ $\mathrm{H}_{2}, \mathrm{H}_{2}-\mathrm{He}$, and $\mathrm{H}_{2}-\mathrm{CH}_{4}$ ) adopt codes developed by Borysow et al. (1985, 1988) and Borysow \& Frommhold (1986). We adopted a He mole fraction of 0.149 from Conrath et al. (1987), and the $\mathrm{CH}_{4}$ tropospheric value of 0.023 derived from Lindal et al. (1987). The Uranus thermal profile is from Orton et al. (2014a). The adopted CO pressure broadening coefficient $\gamma_{\operatorname{co}(8-7)}$ is $0.066 \mathrm{~cm}^{-1} \mathrm{~atm}^{-1}$, with a temperature dependance $n=0.64$ (Sung 2004; Mantz et al. 2005). We note that the continuum level around the $\mathrm{CO}(8-7)$ line probes above $\sim 0.6$ bar pressure level.

\section{Oxygen steady flux}

By making use of our chemical network, treatment of condensation processes, and transport (turbulent and molecular diffusion), we first established the steady influx of $\mathrm{H}_{2} \mathrm{O}, \mathrm{CO}$, and $\mathrm{CO}_{2}$ needed for an overall agreement with the observations from ISO (Feuchtgruber et al. 1997), Herschel (Cavalié et al. 2014), and Spitzer (Orton et al. 2014b), respectively.

For an eddy diffusion coefficient $K(z)=5000 \mathrm{~cm}^{2} \mathrm{~s}^{-1}$, a production rate profile (in molecules $\mathrm{cm}^{-3} \mathrm{~s}^{-1}$ ) of water, carbon monoxide, and carbon dioxide due to the ice grain ablation (Moses \& Poppe 2017) is considered. We tune the integrated flux of each species to better match the available observations for every species. Table 2 lists the water and carbon dioxide fluxes needed in this work to obtain mixing ratios and column densities in good agreement with data. We have also run our model with the integrated ablation rates in Moses \& Poppe (2017) for a comparison with their results. Figure 2 shows 
Table 2. Comparison of theoretical results with available observations versus the integrated flux of oxygen due to ice grain ablation.

\begin{tabular}{|c|c|c|c|c|}
\hline & \multicolumn{4}{|c|}{$\mathrm{H}_{2} \mathrm{O}$} \\
\hline & $\begin{array}{c}\mathrm{ISO}^{a} \\
q, \mathrm{~cm}^{-2}\end{array}$ & $\begin{array}{c}\Phi \\
\mathrm{cm}^{-2} \mathrm{~s}^{-1} \\
\end{array}$ & $\begin{array}{c}q \\
\text { at } 0.03 \mathrm{mbar}\end{array}$ & $\begin{array}{c}\text { Column } \\
\mathrm{cm}^{-2}\end{array}$ \\
\hline & $4.0 \times 10^{-9},(5-12) \times 10^{13}$ & & & \\
\hline TW18 & & $6.0 \times 10^{4}$ & $4.4 \times 10^{-9}$ & $4.3 \times 10^{13}$ \\
\hline \multirow[t]{3}{*}{$\mathrm{MP} 17^{b}$} & & $1.2 \times 10^{5}$ & $7.9 \times 10^{-9}$ & $1.3 \times 10^{14}$ \\
\hline & \multicolumn{4}{|c|}{$\mathrm{CO}_{2}$} \\
\hline & $\begin{array}{l}\text { Spitzer } \\
q, \mathrm{~cm}^{-2}\end{array}$ & $\begin{array}{c}\Phi \\
\mathrm{cm}^{-2} \mathrm{~s}^{-1}\end{array}$ & $\begin{array}{c}q \\
\text { at } 0.15 \mathrm{mbar}\end{array}$ & $\begin{array}{l}\text { Column } \\
\mathrm{cm}^{-2}\end{array}$ \\
\hline & $8.0 \times 10^{-11 c}, 1.7 \pm 0.2 \times 10^{13}$ & & & \\
\hline TW18 & & $4.5 \times 10^{3}$ & $8.3 \times 10^{-11}$ & $9.6 \times 10^{12}$ \\
\hline $\mathrm{MP}^{1} 7^{b}$ & & $3.0 \times 10^{3}$ & $6.0 \times 10^{-11}$ & $6.9 \times 10^{12}$ \\
\hline
\end{tabular}

Notes. ${ }^{(a)}$ Mixing ratio at 0.03 mbar and column density in $\mathrm{cm}^{-2}$ by Feuchtgruber et al. (1997). ${ }^{(b)}$ Our model run with the $\mathrm{CO}_{2} \mathrm{H}_{2} \mathrm{O}$, and $\mathrm{CO}_{2}$ integrated flux as in Moses \& Poppe (2017). ${ }^{(c)}$ Best-fit mixing ratio at $0.15 \mathrm{mbar}$ from photochemical modelling in Orton et al. (2014b).
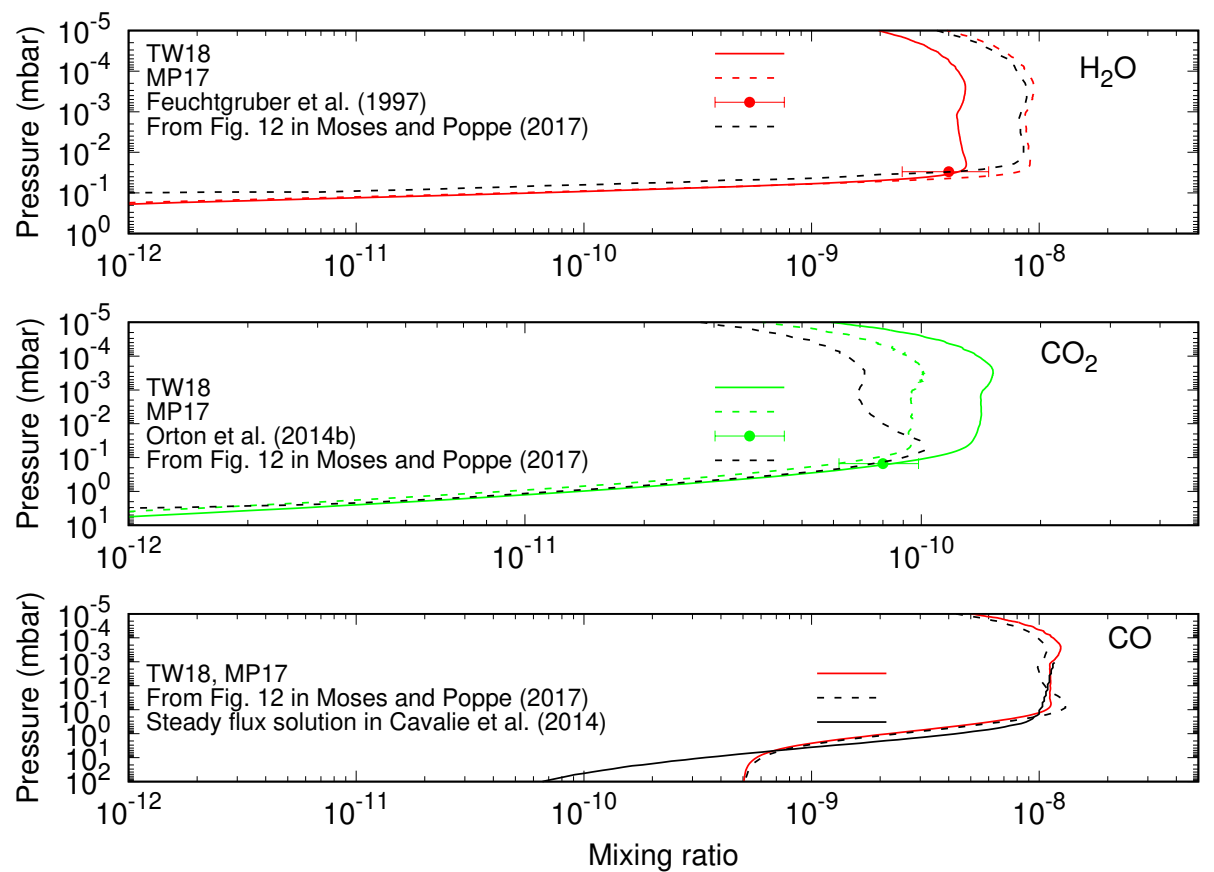

Fig. 2. $\mathrm{H}_{2} \mathrm{O}, \mathrm{CO}_{2}$ and $\mathrm{CO}$ vertical profiles obtained with steady ablation rates in models TW18 and MP17 compared with available ISO, Spitzer and Herschel observations. Bestfit profiles from Moses \& Poppe (2017) are also shown for comparison.

the mixing ratio profiles obtained in both models, TW18 and MP17, as well as the observational data. For the same influx of $\mathrm{CO}, 2.7 \times 10^{5} \mathrm{~cm}^{-2} \mathrm{~s}^{-1}$, our modelled carbon monoxide reproduces that of Moses \& Poppe (2017) at $p \geq 0.1$ mbar and at lower pressure slight discrepancies appear between TW18 and MP17.

However, the use of the integrated flux in Moses \& Poppe (2017) for water and carbon dioxide (model MP17) gives rise to noticeably different mixing ratio values and column densities when compared to our computations in model TW18. More concisely, Moses \& Poppe (2017) require twice the water influx we derive to match the observations $\left(\sim 4.4 \times 10^{-9}\right.$ at 0.03 mbar $)$ and $50 \%$ less in the case of carbon dioxide. Regarding water, Fig. 3 clearly shows that at pressure lower than 0.015 mbar, our model MP17 computes a water mixing ratio profile that largely coincides with that in Moses \& Poppe (2017). However, below this level the two profiles are noticeably different, ours overestimating the water abundance at 0.03 mbar by a factor of $\sim 7$ versus the ISO measurements. A mixing ratio in agreement with ISO observations can be achieved with a water integrated ablation rate of $\sim 6.0 \times 10^{4} \mathrm{~cm}^{-2} \mathrm{~s}^{-1}$ (model TW18). We have also compared the theoretical water column density for water ablation rates $6.0 \times 10^{4}$ and $1.2 \times 10^{5} \mathrm{~cm}^{-2} \mathrm{~s}^{-1}$ (model MP17) resulting in $4.3 \times 10^{13}$ and $1.3 \times 10^{14} \mathrm{~cm}^{-2}$, respectively, approximately within the range given by Feuchtgruber et al. (1997) $(5-12) \times 10^{13} \mathrm{~cm}^{-2}$.

An important difference between models in Moses et al. (2000b) and this work is how condensation is included in the photochemical modelling. Moses et al. (2000b, 2005) follow a sophisticated condensation treatment where a vertical distribution of condensation nuclei and re-sublimation of ices are taken into account. We have considered a very simplified condensation scheme (see Eq. (3)). We note that the water profile derived in this work is highly supersaturated below the condensation level, whereas the profile in Moses \& Poppe (2017) is undersaturated. The vapour pressure law used in this work is from 

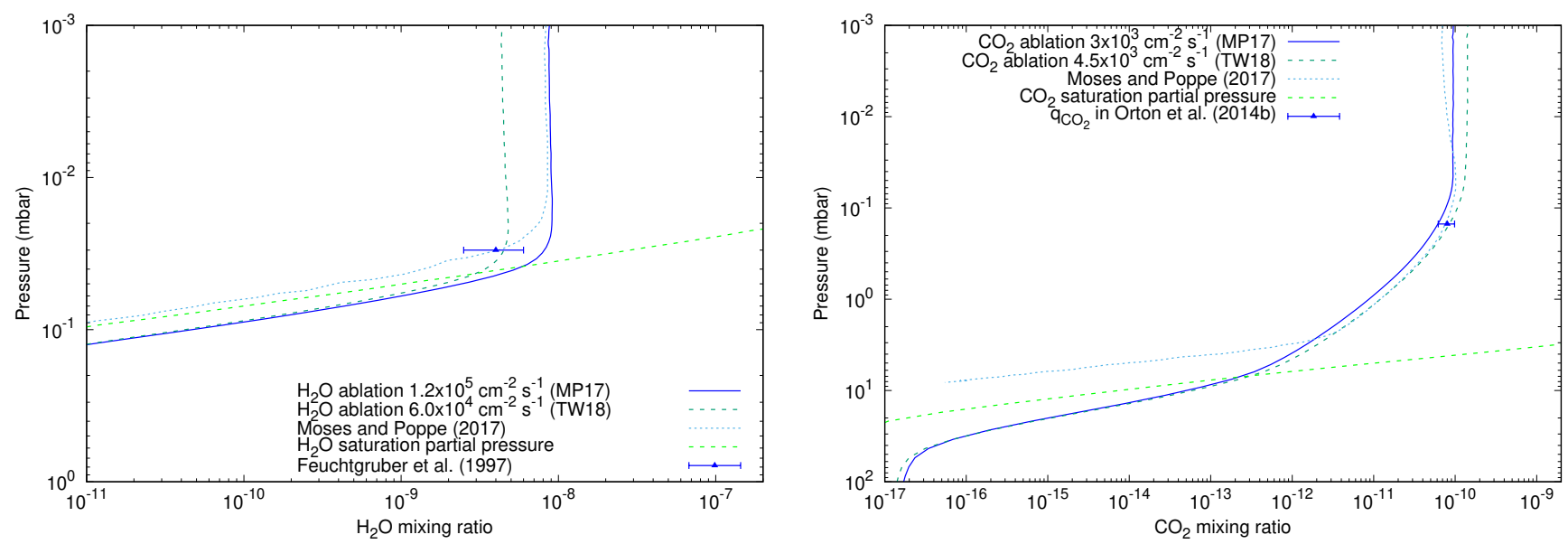

Fig. 3. Comparison of the $\mathrm{H}_{2} \mathrm{O}$ and $\mathrm{CO}_{2}$ profiles obtained in models TW18 and MP17, with ISO (Feuchtgruber et al. 1997) and Spitzer observations (Orton et al. 2014b), respectively. Best fits in Moses \& Poppe (2017) are also shown.

Mauersberger \& Krankowsky (2003):

$\log _{10} P=14.88-\frac{3059.5}{T}$

where the pressure $P$ is in $\mathrm{Pa}$, the temperature $T$ is in $\mathrm{K}$, the expression is valid in the region $165<T<273 \mathrm{~K}$, and we assume it remains valid at lower temperatures. On the other hand, Moses \& Poppe (2017) considered $\log _{10} P=12.537-\frac{2663.5}{T}$ (Marti \& Mauersberger 1993). We have used this law in our model as well, and it does not account for the differences shown in Fig. 2. Since for the same water influx, the vertical mixing ratio profiles of water at $p<0.015$ mbar in MP17 and TW18 coincide, we believe that condensation is the main driver of the discrepancies shown in Fig. 3. Thus, with current information about the water content in the Uranian atmosphere, the influx needed in this work and that in Moses \& Poppe (2017) could both give rise to $\mathrm{H}_{2} \mathrm{O}$ mixing ratio profiles potentially reproducing the ISO observations. Comparison of ISO data with synthetic spectra generated with the theoretical water profiles obtained in this work would help to better determine the $\mathrm{H}_{2} \mathrm{O}$ influx.

We have also analysed why our modelling (TW18) requires $50 \%$ more carbon dioxide to match the Spitzer observations. Unlike the case of $\mathrm{H}_{2} \mathrm{O}$ where using the same influx as Moses \& Poppe (2017) renders basically the same water vertical profile at $p<0.01$ mbar (see Fig. 3), the computed carbon dioxide column abundance shows some dependency on the reaction rate for $\mathrm{CO}+\mathrm{OH} \rightarrow \mathrm{CO}_{2}+\mathrm{H}$ ( $k_{201}$ in Table A.1) in addition to the ice grain integrated flux. Table 3 shows the computed $\mathrm{CO}_{2}$ column density and mixing ratio varying both the integrated oxygen influx and the rate coefficient $k_{201}$ (Moses et al. 2000b; Wakelam et al. 2012). The results indicate that a $\mathrm{CO}_{2}$ influx of $3.0 \times 10^{3} \mathrm{~cm}^{-2} \mathrm{~s}^{-1}$ (see row MP17 in Table 2), despite the $k_{201}$, gives rise to carbon dioxide column abundances $\left(6.9-7.6 \times 10^{12}\right)$ that are considerably below the Spitzer observations $(1.7 \pm 0.4 \times$ $\left.10^{13}\right)$. Therefore, although the $\mathrm{CO}_{2}$ abundance slightly depends on $k_{201}$, this cannot account for the large dissimilarity with Spitzer observations.

Obtaining the same results as in Moses \& Poppe (2017) would require the use of exactly the same chemical network (reactions and their rate coefficients), which is beyond the scope of the current work. As the aim of this paper is to ascertain whether a cometary impact could be responsible for the current presence of oxygen species in the Uranus atmosphere, the conclusions on this open issue can be tackled regardless of the concise value of water and/or carbon dioxide integrated steady flux due to ice grain ablation. Nevertheless, the inconsistency between the required $\mathrm{H}_{2} \mathrm{O}$ influx in Moses \& Poppe (2017) and in these computations with respect to the ISO observations is only $\sim 50 \%$, well within the observational errors.

\section{Cometary impact as the only oxygen source}

In this section we explore in detail whether the time evolution of the material (mostly $\mathrm{CO}$ and $\mathrm{H}_{2} \mathrm{O}$ ) delivered by a cometary impact could be responsible for the observed abundances of these species. Cavalié et al. (2014) and Moses \& Poppe (2017) mention in their works that a cometary source of CO is not an unexpected possibility for Uranus, supplying an external amount of oxygen that is of the same magnitude as the dust influx (Poppe 2016).

We first considered that a cometary impact brought the currently observed carbon monoxide; that is to say, $\mathrm{CO}$ did not diffuse upwards from deep atmospheric levels. As in Moreno et al. (2012) and Lara et al. (2014) and references therein, we assume that this cometary impact behaves like that of Jupiter/Shoemaker-Levy 9 where the cometary oxygen ended up as $\mathrm{CO}$ and $\mathrm{H}_{2} \mathrm{O}$ during the shock chemistry at plume re-entry near the 0.1 mbar and lower pressure levels, and both species have since then slowly diffused vertically. No $\mathrm{CO}_{2}$ was produced in this shock chemistry.

Following Cavalié et al. (2014), discarding CO photochemical processes, that is, using a purely diffusive model with $K(z)=$ $1200 \mathrm{~cm}^{2} \mathrm{~s}^{-1}$, considering that a comet of $640 \mathrm{~m}$ diameter (i.e. $9.3 \times 10^{15} \mathrm{CO}$ molecules $\mathrm{cm}^{-2}$ or $3.5 \times 10^{13} \mathrm{~g}$ were produced by the cometary impact in the Uranus atmosphere) hit the planet $370 \mathrm{yr}$ ago, our CO mixing ratio profile perfectly matches that in Fig. 2 of Cavalié et al. (2014). These results validate both diffusion models.

Our work then focused on determining the impactor size (diameter $D$ in $\mathrm{km}$ ) and when it occurred ( $t_{\text {impact }} \mathrm{yr}$ ago) in order to obtain a $\mathrm{CO}$ mixing ratio whose synthetic spectrum matches the Herschel observations (Cavalié et al. 2014) and $q_{\mathrm{CO}}<2.0 \times 10^{-9}$ in the $200-100$ mbar range (Teanby \& Irwin 2013). For this modelling, we fixed the eddy diffusion coefficient to our nominal value of $K(z)=5000 \mathrm{~cm}^{2} \mathrm{~s}^{-1}$.

To determine which stratospheric $\mathrm{CO}$ mixing ratio best matches the observations, as a starting point, we arbitrarily considered an impactor of $2 \mathrm{~km}$ in diameter and let the system evolve 
Table 3. $\mathrm{CO}_{2}$ column density and mixing ratio obtained for several oxygen influx and $\mathrm{CO}+\mathrm{OH} \rightarrow \mathrm{CO}_{2}+\mathrm{H}$ reaction rate coefficients.

\begin{tabular}{lccccc}
\hline \hline & \multicolumn{2}{c}{$k_{201}$ as in Table A.1 } & & \multicolumn{2}{c}{$k_{201}=1.5 \times 10^{-13} \mathrm{~cm}^{3} \mathrm{~s}^{-1}$} \\
\cline { 2 - 3 } \cline { 5 - 6 } Model & $q^{a}$ at $0.15 \mathrm{mbar}$ & Column $\left(\mathrm{cm}^{-2}\right)$ & & $q^{a}$ at $0.15 \mathrm{mbar}$ & Column $\left(\mathrm{cm}^{-2}\right)$ \\
\hline TW18 & $8.3 \times 10^{-11}$ & $9.6 \times 10^{12}$ & & $8.8 \times 10^{-11}$ & $1.0 \times 10^{13}$ \\
MP17 & $6.0 \times 10^{-11}$ & $6.9 \times 10^{12}$ & & $6.7 \times 10^{-11}$ & $7.6 \times 10^{12}$ \\
TW18a & & & & $9.4 \times 10^{-11}$ & $1.1 \times 10^{13}$ \\
TW18a $^{b}$ & $8.6 \times 10^{-11}$ & $9.9 \times 10^{12}$ & & \\
\hline
\end{tabular}

Notes. TW18 and MP17 refer to models with nominal values of the oxygen-bearing influx (see Sect. 4). ${ }^{(a)} \mathrm{CO}_{2}$ best-fit mixing ratio at 0.15 mbar from photochemical modelling in Orton et al. (2014b) is $8.0 \times 10^{-11}$. ${ }^{(b)}$ Ice grain ablation influx giving rise to $1.2 \times 10^{5}$ and $4.5 \times 10^{3} \mathrm{~cm}^{-2} \mathrm{~s}^{-1}$ for $\mathrm{H}_{2} \mathrm{O}$ and $\mathrm{CO}_{2}$, respectively.

over several hundred years (i.e. to determine when the impact happened, $\left.t_{\text {impact }}\right)$ to obtain several $q_{\mathrm{CO}}$ profiles that are used as input in the sub-mm radiative transfer computations (see Sect. 3 ). Aiming for a realistic study, we allowed chemistry to distribute the oxygen influx among the different species considered in the model (see Sect. 2). For those species whose resulting partial pressure is higher than that allowed by the vapour pressure law, an additional term loss due to condensation is considered following Eq. (3).

The outcome of this sensitivity test indicates that a $\mathrm{CO}$ relative abundance of $7.0 \times 10^{-9}$ at 0.4 mbar allows an optimal match of the line core and wings. Table 4 lists different cases where $\left(D, t_{\text {impact }}\right)$ have been tuned to obtain $q_{\mathrm{CO}}=(7.0 \pm 0.1) \times 10^{-9}$ at the $\sim 0.4$ mbar region, the delivered CO mass (in $\mathrm{g}$ ), and the CO mixing ratio obtained in $200-100$ mbar. The resulting profiles in the 200-100 mbar region reflect that larger impactors give rise to larger $\mathrm{CO}$ abundances although below the upper limits in Teanby \& Irwin (2013). Table 4 shows that the solution is degenerate; in other words, the same stratospheric CO mixing ratio abundance can be obtanied with pairs of $\left(D, t_{\text {impact }}\right)$ that represent larger impacts having taken place longer ago, or smaller impactors occurred more recently. For instance, the temporal evolution of the material delivered by a cometary impact indicates that the $\mathrm{CO}$ currently observed in the Uranus stratosphere could be due to a comet nucleus of $3.5 \mathrm{~km}$ diameter that hit the planet 822 yr ago.

Figure 4 shows the comparison of the measured spectra and the modelled radiative transfer as a function of the different $\mathrm{CO}$ vertical distribution resulting from steady ice grain ablation and cases 3 and 4 for cometary impact. Any other of the cases in Table 4 will give rise to a $\mathrm{CO}$ mixing ratio of $\sim 7.0 \times 10^{-9}$ at the 0.4 mbar pressure level that will give good match to the Herschel data. Stratospheric CO mixing ratio profiles with an abundance larger than the value in the pressure range probed by Herschel (i.e. between 3 and 0.4 mbar) can in principle be discarded as they will overestimate the observations. Similarly, the tropospheric CO mixing ratio profile has to be lower than the upper limit $2.1 \times 10^{-9}$ established by Teanby \& Irwin (2013).

Equations (14) and (15) in Zahnle et al. (2003), adapted to Uranus where the impact frequency is $\sim 4$ times smaller than on Jupiter, allow us to plot the frequency of impact versus the impactor size. Figure 5 displays two different scenarios depending on the origin of the impactors: the size-number distribution of impactors is like that inferred at Jupiter (ecliptic comets), and those impactors more representative of nearly isotropic comets (as long-period or Halley-type comets). Zahnle et al. (2003) conclude that known craters on the Saturnian and Uranian satellites are consistent with either case; that is, both kinds of impactors are in the Uranian system and they could have entered the Uranus atmosphere. Also, Zahnle et al. (2003) assume that the impact rate on Uranus is $\sim 0.00125$ comets per year (i.e. one impact every $\sim 800 \mathrm{yr}$ ) with $D>1.5 \mathrm{~km}$ with an uncertainty to a factor of 6 . Hence, to constrain the most likely size of the impactor and time, $\left(D, t_{\text {impact }}\right)$, that could be responsible for the $\mathrm{CO}$ in the Uranian stratosphere, we can follow two approaches: (i) either we consider that one impact takes place every $\sim 800 \mathrm{yr}$, the size of the impactor being $D>1.5 \mathrm{~km}$, and this is fulfilled in cases 4,5 , and 6 (and every other case where $D$ and $t_{\text {impact }}$ are larger with the only constraint that the tropospheric $\mathrm{CO}$ mixing ratio remains below the upper limit in Teanby \& Irwin 2013), or (ii) we distinguish the two types of impactors-those at ecliptic orbits (known as Uranus A), or those in nearly isotropic orbits (known as Uranus B) - to assess the origin of the impactor on the planet and the subsequent shock chemistry that gave rise to the currently detected $\mathrm{CO}$. In the latter consideration, impactors with $\sim 1<D<2 \mathrm{~km}$ and $\sim 450<t_{\text {impact }}<630 \mathrm{yr}$ are in the range allowed by the curves in Fig. 5 .

The cometary impact delivers 10 times less $\mathrm{H}_{2} \mathrm{O}$ than $\mathrm{CO}$, and no $\mathrm{CO}_{2}$. The resulting water and carbon dioxide profiles for cometary impacts pertaining to cases $0-3$ in Table 4 are shown in Fig. 6 together with ISO and Spitzer measurements.

As most of the oxygen released by a shock chemistry induced during the cometary impact is in the form of $\mathrm{CO}(90 \%)$ and $\mathrm{H}_{2} \mathrm{O}(10 \%)$, the only source of $\mathrm{CO}_{2}$ is subsequent oxygen chemistry. The process $\mathrm{CO}+\mathrm{OH} \rightarrow \mathrm{CO}_{2}+\mathrm{H}$ produces negligible amounts of $\mathrm{CO}_{2}$ as the abundance of the reactants is very low at the $p<0.5$ mbar once the evolution time is such that $\mathrm{CO}$ stratospheric mixing ratio matches the Herschel data and $\mathrm{H}_{2} \mathrm{O}$ is highly reduced in the upper atmosphere where its photolysis gives rise to $\mathrm{OH}$. The resulting $\mathrm{CO}_{2}$ integrated column densities range from $3.9 \times 10^{10}$ to $2.4 \times 10^{11} \mathrm{~cm}^{-2}$ for the cases in Table 4, clearly well below the Spitzer measurements (Orton et al. 2014b) $\left(1.7 \pm 0.4 \times 10^{13}\right)$. Similarly, our computed mixing ratio is considerably lower than $8 \times 10^{-11}$ in Orton et al. (2014b).

Feuchtgruber et al. (1997) derived a relative abundace of $6-14 \times 10^{-9}$ at $p<0.03$ mbar. The cometary impact delivers the $\mathrm{CO}$ and $\mathrm{H}_{2} \mathrm{O}$ at $p<0.1$ mbar (Lellouch et al. 2005). The $\mathrm{H}_{2} \mathrm{O}$ profile resulting from the time evolution of the water delivered by a cometary impact is noticeably below the ISO observations (see Fig. 6). The $\mathrm{H}_{2} \mathrm{O}$ rapidly dissociates given the poor UV shielding by hydrocarbons absorbing at the same wavelengths as water does, and it is rapidly transported downwards as condensation represents the most important sink for this species between 3.1 bar and 2.6 mbar. The gaseous water deposited by the impact diffuses downward to the 0.03 mbar region to give a mixing ratio of $6-14 \times 10^{-9}$ in only $\sim 50 \mathrm{yr}$. In that time 
Table 4. Impactor size and time to reproduce CO available observations and upper limit, respectively (Cavalié et al. 2014; Teanby \& Irwin 2013).

\begin{tabular}{lccccc}
\hline \hline Case & $\begin{array}{c}D \\
(\mathrm{~km})\end{array}$ & $\begin{array}{c}t_{\text {impact }} \\
\text { yr ago }\end{array}$ & $\begin{array}{c}\text { CO mass } \\
(\mathrm{g})\end{array}$ & $0.5-0.3 \mathrm{mbar}$ & \multicolumn{2}{c}{$q_{\mathrm{CO}}$} \\
\hline $0^{a}$ & 0.64 & 250 & $3.5 \times 10^{13}$ & $(7.0 \pm 0.1) \times 10^{-9}$ & $(5.2-5.3) \times 10^{-10}$ \\
1 & 1.5 & 524 & $4.6 \times 10^{14}$ & $(7.0 \pm 0.1) \times 10^{-9}$ & $(6.5-6.8) \times 10^{-10}$ \\
2 & 1.6 & 549 & $5.7 \times 10^{14}$ & $(7.0 \pm 0.1) \times 10^{-9}$ & $(6.7-7.0) \times 10^{-10}$ \\
3 & 2.0 & 629 & $1.1 \times 10^{15}$ & $(7.0 \pm 0.1) \times 10^{-9}$ & $(7.4-7.8) \times 10^{-10}$ \\
4 & 3.5 & 822 & $5.6 \times 10^{15}$ & $(7.0 \pm 0.1) \times 10^{-9}$ & $(9.8-10.0) \times 10^{-10}$ \\
5 & 4.0 & 872 & $8.6 \times 10^{15}$ & $(7.0 \pm 0.1) \times 10^{-9}$ & $(10.1-11.4) \times 10^{-10}$ \\
6 & 4.9 & 950 & $1.6 \times 10^{16}$ & $(7.0 \pm 0.1) \times 10^{-9}$ & $(12.1-13.0) \times 10^{-10}$ \\
\hline
\end{tabular}

Notes. ${ }^{(a)}$ Model run for a size of the impactor as in Cavalié et al. (2014), the eddy diffusion coefficient being $K(z)=5000 \mathrm{~cm}^{2} \mathrm{~s}^{-1}$, our nominal value for $K(z)$, unlike in Cavalié et al. (2014) who consider $1200 \mathrm{~cm}^{2} \mathrm{~s}^{-1}$. The evolution time needed to obtain a CO mixing ratio that matches the Herschel observations is shorter than the $370 \mathrm{yr}$ needed in Cavalié et al. (2014) mainly due to a higher eddy diffusion coefficient.
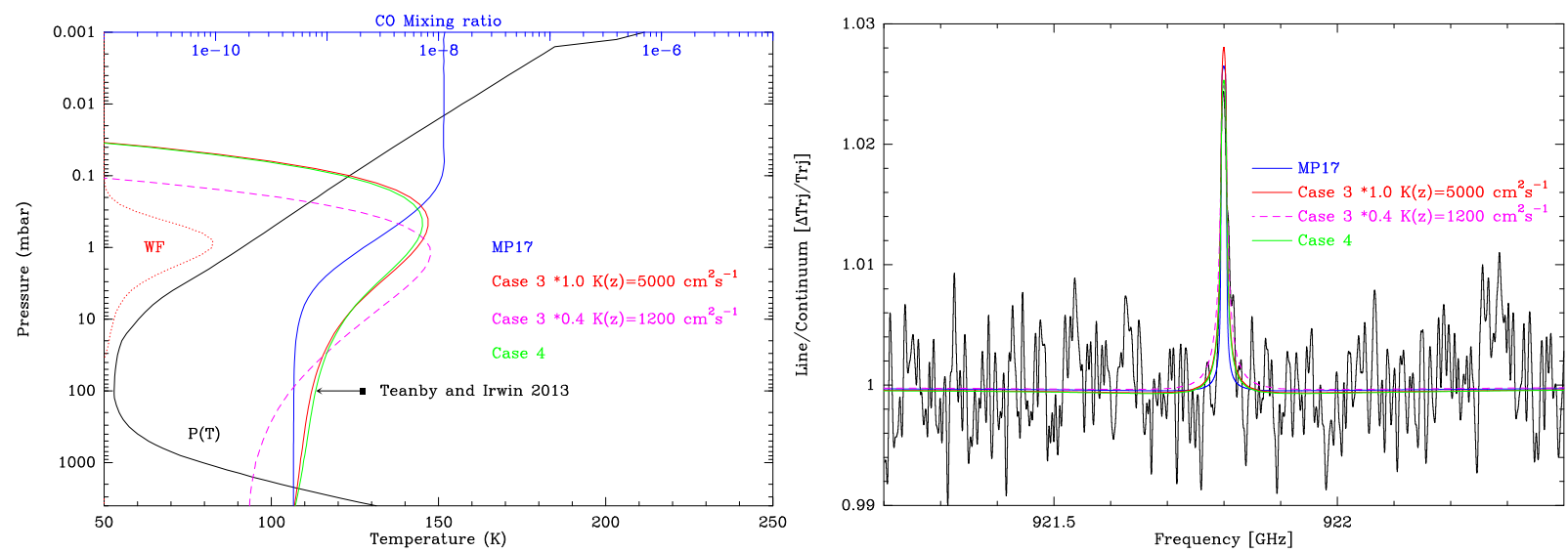

Fig. 4. Comparison of the CO line observed with Herschel and the spectra computed with the resulting CO vertical profile pertaining to model MP17, nominal case $3\left(K(z)=5000 \mathrm{~cm}^{2} \mathrm{~s}^{-1}\right), 40 \%$ of $q_{\mathrm{CO}}$ resulting from case 3 with $K(z)=1200 \mathrm{~cm}^{2} \mathrm{~s}^{-1}$, and case 4 in Table 4 . WF denotes the weighting function at the line centre.

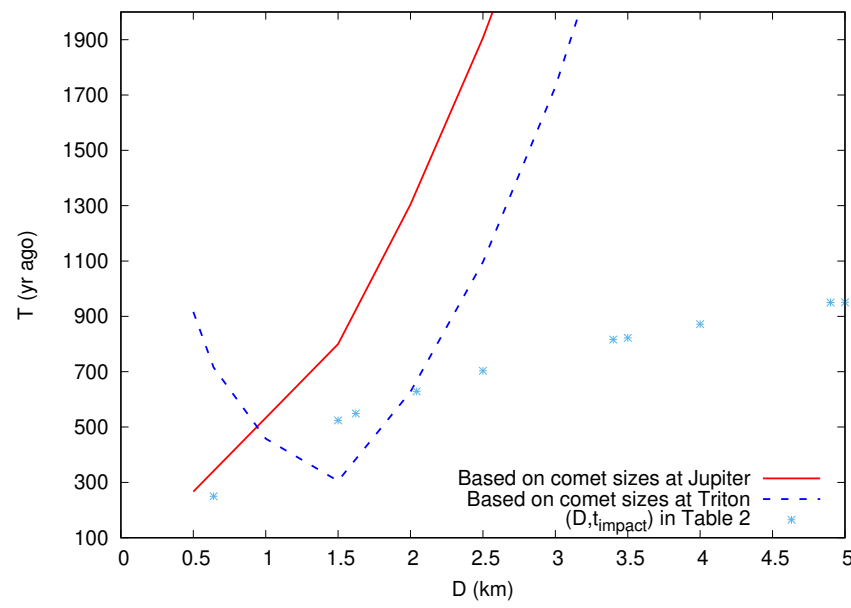

Fig. 5. Inverse of the impact frequency (in units of years ago) versus impactor size $D$ on Uranus for two different scenarios: impactors in which the size-number distribution of impactors represent ecliptic comets (red solid line), and nearly isotropic comets such as long-period and Halley-type comets (blue dashed line; see Zahnle et al. 2003, and references therein). Stars show the $\left(D, t_{\text {impact }}\right)$ from Table 4 that allows for an optimal match of Herschel $\mathrm{CO}$ data in the stratosphere and below the upper limit in the troposphere (Teanby \& Irwin 2013).

lapse, $\mathrm{CO}$ abundance at $\sim 0.4 \mathrm{mbar}$ is orders of magnitude higher than $\sim 7.0 \times 10^{-9}$ as it takes centuries to diffuse to the atmospheric region where Herschel has detected it (Cavalié et al. 2014). Figure 7 displays the water, carbon monoxide, and carbon dioxide profiles obtained for impactors of 1.6 and $2.0 \mathrm{~km}$ diameter. The evolution time is set to $\sim 50 \mathrm{yr}$, which provides an $\mathrm{H}_{2} \mathrm{O}$ mixing ratio matching the ISO observations. However, the carbon monoxide and carbon dioxide noticeably overestimate the Herschel and Spitzer measurements, respectively.

From this analysis, we can conclude that the current $\mathrm{CO}$ stratospheric abundance can derive from a cometary impact that occurred several centuries ago, whereas the observed water and carbon dioxide observed mixing ratios cannot be explained by this event alone. In summary, from the modelling presented in this section, we can discard a single cometary impact as the only origin of the current stratospheric $\mathrm{H}_{2} \mathrm{O}$ and $\mathrm{CO}_{2}$ measured abundances, whereas $\mathrm{CO}$ best fit to Herschel observations can be obtained if a comet of $\sim 1.2-2.0 \mathrm{~km}$ diameter impacted the planet $\sim 450-630$ yr ago, or a large impact $(D \sim 3.5 \mathrm{~km})$ took place $\sim 800$ yr ago.

Considering an eddy diffusion coefficient $K(z)=$ $1200 \mathrm{~cm}^{2} \mathrm{~s}^{-1}$ (as in Cavalié et al. 2014) and assuming that the shock chemistry produces $\mathrm{CO}$ at the $0.1 \mathrm{mbar}$ level, the diffusion times needed to reach $q_{\mathrm{CO}} \sim 7.0 \times 10^{-9}$ at 0.4 mbar are considerably longer than the values listed in Table 4 . More concisely, for $D=1.6 \mathrm{~km}$, the diffusion time is $\sim 900 \mathrm{yr}$, whereas for $D=3.5 \mathrm{~km}, t_{\text {impact }} \sim 1600 \mathrm{yr}$ ago. In principle, these old impacts cannot be discarded according to Zahnle et al. (2003). However, the CO stratospheric profiles render 

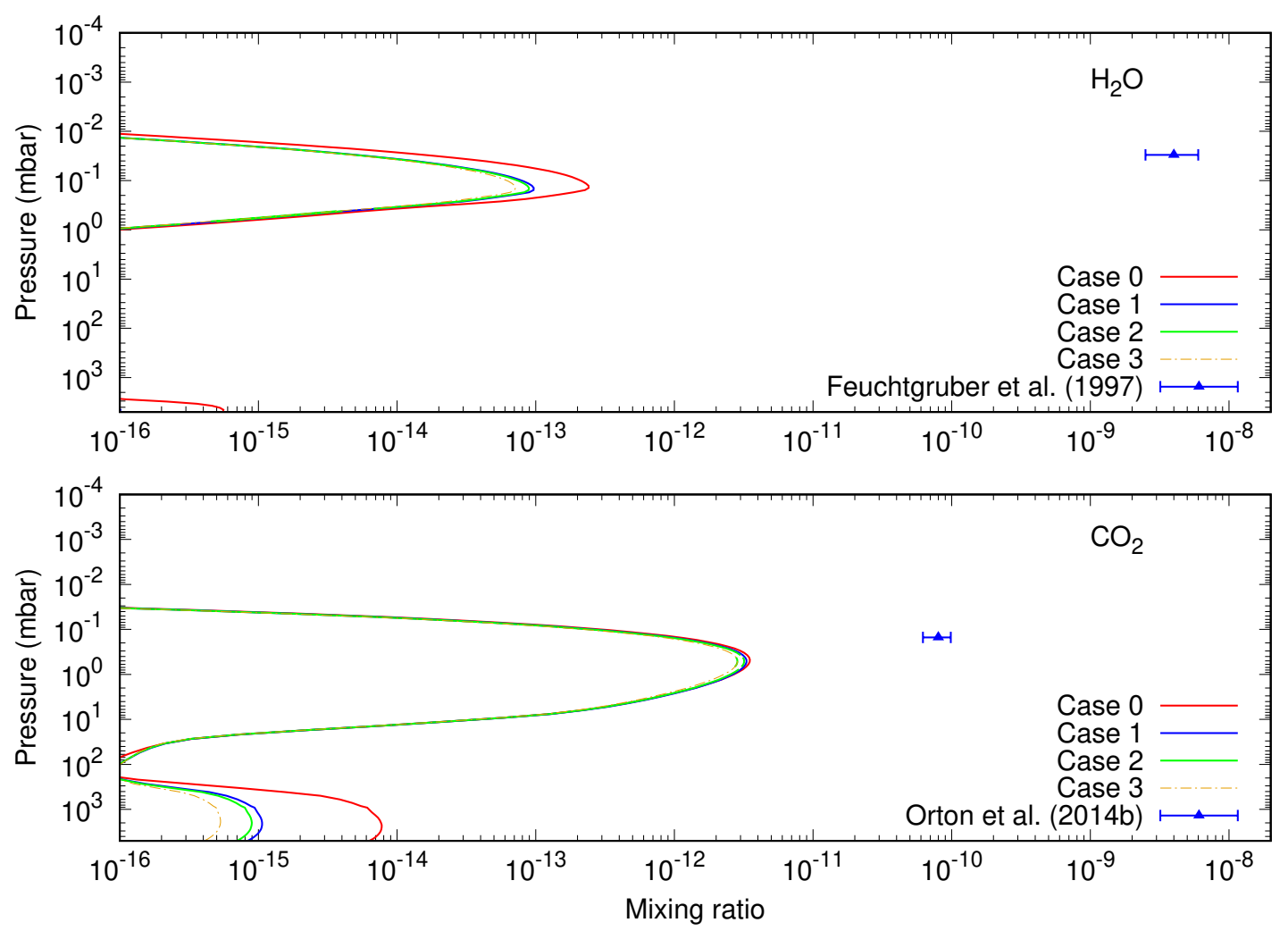

Fig. 6. Vertical profiles of $\mathrm{H}_{2} \mathrm{O}$ and $\mathrm{CO}_{2}$ derived from the time-dependent model assuming three different scenarios for a cometary impact on Uranus (cases 0-3 in Table 4) delivering 10 times less $\mathrm{H}_{2} \mathrm{O}$ than $\mathrm{CO}$, and no $\mathrm{CO}_{2}$. Available observational data on $\mathrm{H}_{2} \mathrm{O}(\mathrm{Feuchtgruber}$ et al. 1997) and best-fit $q_{\mathrm{CO}_{2}}$ matching the Spitzer measured column density (Orton et al. 2014b) are also shown. Photochemical, condensation, turbulent transport with $K(z)=5000 \mathrm{~cm}^{2} \mathrm{~s}^{-1}$, and molecular diffusion are taken into account.
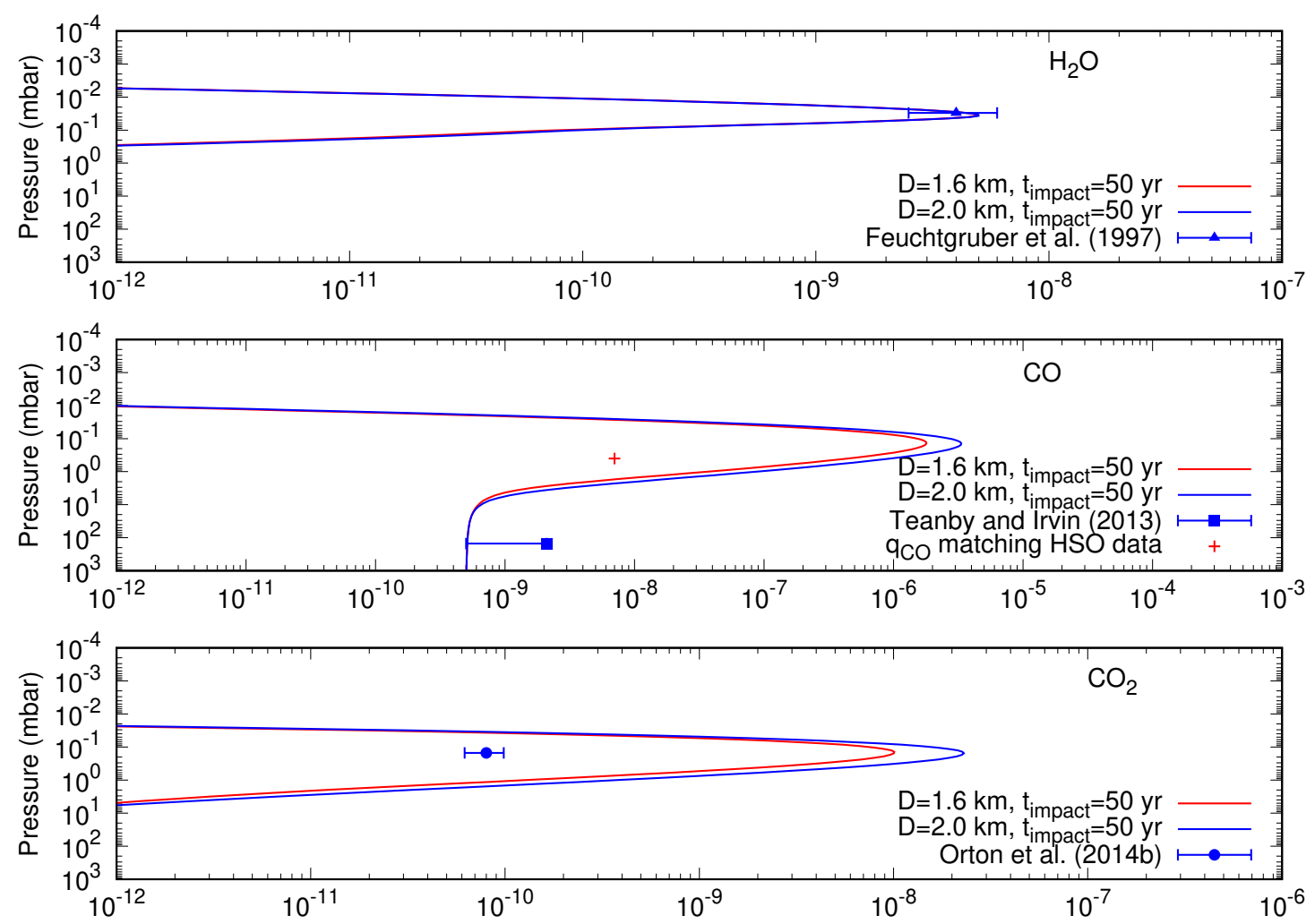

Fig. 7. Mixing ratio profiles of $\mathrm{H}_{2} \mathrm{O}, \mathrm{CO}$, and $\mathrm{CO}_{2} \sim 50 \mathrm{yr}$ after a comet nucleus of size 1.6 and $2.0 \mathrm{~km}$ impacted Uranus. The evolution time is tuned to reproduce the water ISO observations, which in turn produces carbon monoxide and carbon dioxide clearly above the available measurements. Photochemical, condensation, turbulent transport with $K(z)=5000 \mathrm{~cm}^{2} \mathrm{~s}^{-1}$, and molecular diffusion are taken into account. 
synthetic spectra that are more intense and broader than the observed spectrum. Nevertheless, decreasing the $\mathrm{CO}$ abundance by $40 \%$, the resulting profile can fit the Herschel observations (see Fig. 4).

\section{Combined oxygen source: meteoroid ablation and cometary impact}

The best-fit model to $\mathrm{CO}, \mathrm{H}_{2} \mathrm{O}$, and $\mathrm{CO}_{2}$ by Moses \& Poppe (2017) requires a total oxygen influx rate that is a factor of 4 higher than original predictions from the ablation of ice grains $\left(4.0 \times 10^{5}\right.$ versus $\left.8.9 \times 10^{4} \mathrm{~cm}^{-2} \mathrm{~s}^{-1}\right)$. They give different arguments to explain the origin of this mismatch, for example uncertainties in the ablation modelling or additional external sources of oxygen to Uranus, such as satellite/ring debris or cometary impact. In this section, we analyse whether a combined source of oxygen entering the Uranus atmosphere can reproduce the water, carbon monoxide, and carbon dioxide observations.

\section{1. $\mathrm{H}_{2} \mathrm{O}$ and $\mathrm{CO}_{2}$ steady source and $\mathrm{CO}$ of cometary origin}

This scenario contemplates a combined source in which water is mainly produced by the injection rate (in molecules $\mathrm{cm}^{-3} \mathrm{~s}^{-1}$ ) shown in Fig. 6 of Moses \& Poppe (2017) due to the ablation of ice grains. We considered an $\mathrm{H}_{2} \mathrm{O}$ integrated ablation rate of $6.0 \times 10^{4} \mathrm{~cm}^{-2} \mathrm{~s}^{-1}$ because in our study, and for the case of a steady oxygen source, it is the best value that reproduces the ISO observations (Feuchtgruber et al. 1997; see Sect. 4). The gas-gas chemistry contemplated in our chemical scheme gives contributes very little to the overall production of water. On the other hand, carbon monoxide and water originate from a cometary impact in a ratio of 90:10. In this line, we have arbitrarily chosen case 3 in Table $4\left(D=2.0 \mathrm{~km}, t_{\text {impact }}=630 \mathrm{yr}\right.$ ago $)$. We note that any other cometary impact case studied in Sect. 5 leads to the same general conclusions. The upper panel of Fig. 8 displays the results of this combined source of oxygen entering the Uranus atmosphere. As expected, the predicted $\mathrm{CO}$ and $\mathrm{H}_{2} \mathrm{O}$ perfectly match the observations, but carbon dioxide is severely underestimated: the reaction $\mathrm{R} 201\left(\mathrm{CO}+\mathrm{OH} \rightarrow \mathrm{CO}_{2}+\mathrm{H}\right)$ cannot efficiently proceed as the two involved reactants are present at different atmospheric regions. This makes the $\mathrm{CO}_{2}$ production very inefficient. Additionally, carbon dioxide irreversibly condenses between 410 and 7 mbar. The measured column density of $\mathrm{CO}_{2}$ by Spitzer can be achieved by considering a carbon dioxide integrated external flux of $4.5 \times 10^{3} \mathrm{~cm}^{-2} \mathrm{~s}^{-1}$ due to ice grain ablation (lower panel in Fig. 8). In this way, the currently available set of water, carbon monoxide, and carbon dioxide observations can be reproduced by invoking a cometary impact $\sim 630$ yr ago bringing $1.1 \times 10^{15}$ gr of $\mathrm{CO}$, and an external steady source of $4.5 \times 10^{3}$ and $6.0 \times 10^{4} \mathrm{~cm}^{-2} \mathrm{~s}^{-1}$ of $\mathrm{CO}_{2}$ and $\mathrm{H}_{2} \mathrm{O}$, respectively.

\subsection{Steady source of $\mathrm{H}_{2} \mathrm{O}, \mathrm{CO}$, and $\mathrm{CO}_{2}$, and cometary impact delivering $\mathrm{CO}$}

We also studied a combined $\mathrm{CO}$ source, namely carbon monoxide produced by a cometary impact as well as an oxygen steady source due to ice grain ablation that also injects water and carbon dioxide into the Uranus atmosphere. From a physical point of view there is no reason to discard such a scenario. Models are run by fixing the water and the carbon dioxide steady influx to the values needed to match current observations (see above and Sect. 4), $6.0 \times 10^{4}$ and $4.5 \times 10^{3} \mathrm{~cm}^{-2} \mathrm{~s}^{-1}$,

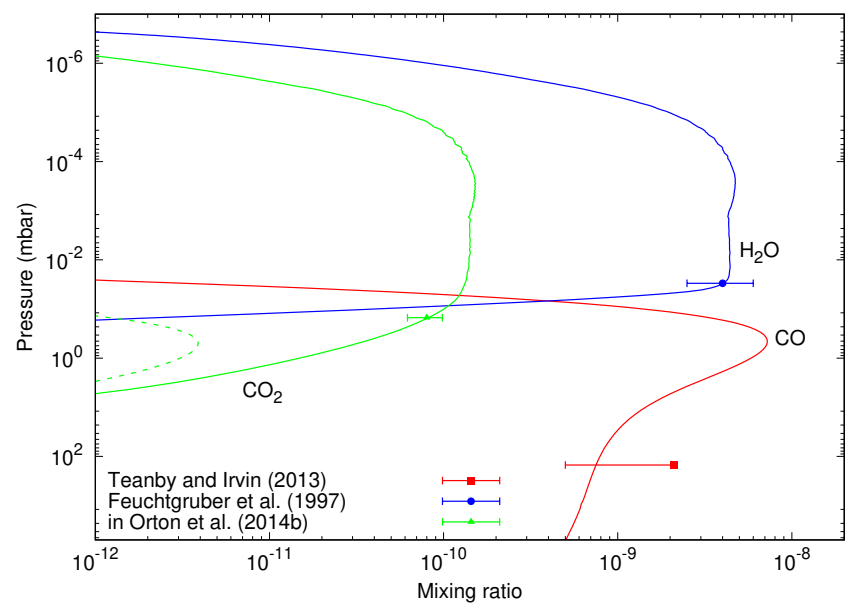

Fig. 8. Vertical profiles of $\mathrm{H}_{2} \mathrm{O}, \mathrm{CO}$, and $\mathrm{CO}_{2}$ derived from the timedependent model under these assumptions: (i) $1.1 \times 10^{15}$ gr of $\mathrm{CO}$ are brought to the planet via a cometary impact $\sim 630$ yr ago (case 3 in Table 4), and (ii) vapour water input is due to the ablation of ice grains (Moses \& Poppe 2017) with an integrated rate of $6.0 \times 10^{4} \mathrm{~cm}^{-2} \mathrm{~s}^{-1}$. Red solid line: $\mathrm{CO}$, blue solid line: $\mathrm{H}_{2} \mathrm{O}$, dashed green line: $\mathrm{CO}_{2}$ only produced by chemical processes, and green solid line: carbon dioxide when an integrated ice grain ablation rate of $4.5 \times 10^{4} \mathrm{~cm}^{-2} \mathrm{~s}^{-1}$ is considered as well.

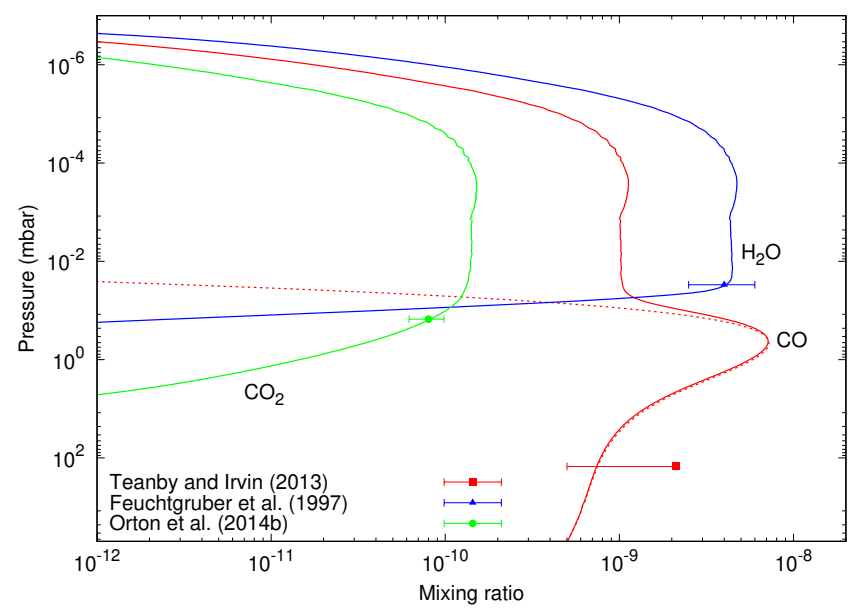

Fig. 9. Mixing ratio profiles of $\mathrm{H}_{2} \mathrm{O}, \mathrm{CO}$, and $\mathrm{CO}_{2}$ obtained when a production rate due to ice grain ablation for every species with integrated rates of $6.0 \times 10^{4}, 2.45 \times 10^{4}$ and $4.5 \times 10^{3} \mathrm{~cm}^{-2} \mathrm{~s}^{-1}$ is taken into account. An additional source of cometary $\mathrm{CO}$ is considered as well, the impactor size is $D=2 \mathrm{~km}$, and the evolution time needed to match the Herschel observations is $639 \mathrm{yr}$. The red dashed line refers to the carbon monoxide profile resulting from the simulation of case 2 (see Table 4).

respectively. Thus, assuming as a total oxygen influx the nominal result in Moses \& Poppe (2017) $\left(8.9 \times 10^{4} \mathrm{~cm}^{-2} \mathrm{~s}^{-1}\right)$, carbon monoxide has to be produced by ice grain ablation at a rate of $2.45 \times 10^{4} \mathrm{~cm}^{-2} \mathrm{~s}^{-1}$. This gives the following relative influx rates $67 \% \mathrm{H}_{2} \mathrm{O}, 28 \% \mathrm{CO}$, and $5 \% \mathrm{CO}_{2}$. In addition to this $\mathrm{CO}$ influx, we consider that a comet nucleus of $\sim 2 \mathrm{~km}$ (case 3 in Table 4) impacted the planet. After 639 yr the stratospheric carbon monoxide abundance allows for a good match of Herschel measurements, as shown in Fig. 9. The resulting $\mathrm{CO}$ vertical profile in the pressure range $p>0.05 \mathrm{mbar}$ reflects the downward-transported carbon dioxide over $639 \mathrm{yr}$, whereas at lower pressures the vertical profile reflects the steady influx. 

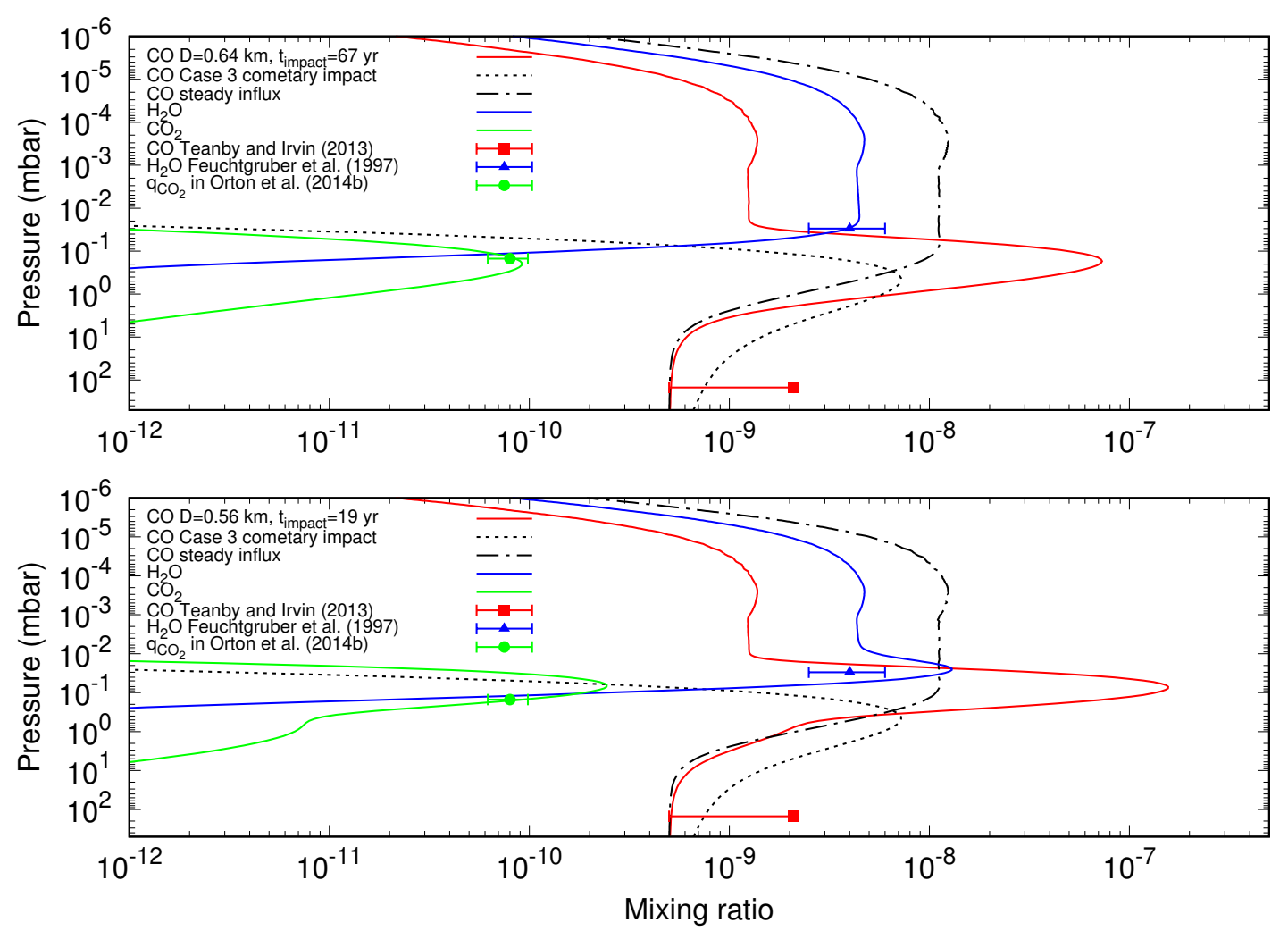

Fig. 10. Mixing ratio profiles of the most abundant oxygen species in the Uranus atmosphere assuming an oxygen combined source due to ice grain ablation and cometary impact. Upper panel: mixing ratio profiles resulting from assuming $\mathrm{H}_{2} \mathrm{O}$ and CO influx of $6.0 \times 10^{4}$ and $2.9 \times 10^{4} \mathrm{~cm}^{-2} \mathrm{~s}^{-1}$, respectively. Additionally, an impactor of $0.64 \mathrm{~km}$ in diameter hits the planet delivering only $\mathrm{CO}$ (see Table 4 ). Carbon dioxide is produced by chemical reactions. The evolution time of the material delivered by the comet is tuned to produce a $\mathrm{CO}_{2}$ abundance compatible with Spitzer observations resulting into $t_{\text {impact }}=67 \mathrm{yr}$. On the other hand, $\mathrm{CO}$ largely overestimates the data. Lower panel: as above, but the size of the impactor is reduced to $0.56 \mathrm{~km}$ to inject a smaller amount of $\mathrm{CO}$ in the atmosphere. The evolution time needed to match the $\mathrm{CO}_{2}$ observations is $19 \mathrm{yr}$ giving rise to a $\mathrm{CO}$ mixing ratio $\sim 5 \times 10^{-9}$ at $0.4 \mathrm{mbar}$, whereas $\mathrm{H}_{2} \mathrm{O}$ largely overestimates ISO data.

\subsection{Steady source of $\mathrm{H}_{2} \mathrm{O}$ and $\mathrm{CO}$, and cometary impact delivering $\mathrm{CO}$}

Another possible scenario is to assume that only water and carbon monoxide are produced during the ice grain ablation with influxes of $6.0 \times 10^{4}$ and $2.9 \times 10^{4} \mathrm{~cm}^{-2} \mathrm{~s}^{-1}$, respectively. The total oxygen influx is thus the nominal result in Moses \& Poppe (2017), $8.9 \times 10^{4} \mathrm{~cm}^{-2} \mathrm{~s}^{-1}$. The carbon dioxide chemical production in this model run, i.e. no external source of $\mathrm{CO}_{2}$, does not give rise to its measured abundance. Therefore, our aim is to match the $\mathrm{CO}_{2}$ observations by determining when an impactor collided with the planet delivering $\mathrm{CO}$ and $\mathrm{H}_{2} \mathrm{O}$ in the usual proportion (90:10) so that $\mathrm{CO}_{2}$ could attain the observed mixing ratio. As an example, we consider case 0 in Table $4, D=0.64 \mathrm{~km}, 3.5 \times 10^{13} \mathrm{gr}$ of CO delivered to the planet and $\mathrm{CO}_{2}$ only produced by the chemical reaction $\mathrm{CO}+\mathrm{OH} \rightarrow$ $\mathrm{CO}_{2}+\mathrm{H}$. After $67 \mathrm{yr}$ of chemical and dynamical evolution, the $\mathrm{CO}_{2}$ stratospheric mixing ratio coincides with the value derived from the Spitzer observations. However, the profile that matches the Spitzer observations more closely according to Orton et al. (2014b) is dramatically different from that obtained in this simulation. These photochemical models alone cannot conclude whether the carbon dioxide profile shown in the lower panel of Fig. 10 agrees with Spitzer data. Synthetic spectra should be computed and compared with observational data, and this is beyond the scope of the current paper. Whereas $\mathrm{CO}_{2}$ might reproduce the observations (with the caveats noted above), the $\mathrm{CO}$ abundance at 0.4 mbar is one order of magnitude larger than
Herschel data indicate (see upper panel in Fig. 10). Given the degeneracy noted in Sect. 5, larger impacts should have taken place longer ago; however, they are not favoured as the stratospheric CO would considerably exceed the measurements. In order to have a stratospheric CO mixing ratio of $\sim 7.0 \times 10^{-9}$ at 0.4 mbar, the impactor size has to be smaller $(D=0.56 \mathrm{~km})$ and the event has to have occurred only $19 \mathrm{yr}$ ago. This scenario is fatal for the computed $\mathrm{H}_{2} \mathrm{O}$ abundance as it surpasses the measurements by a factor of 10 (see lower panel in Fig. 10). We note that the water diffusion time is $\sim 60 \mathrm{yr}$, and the evolution time requested in this simulation to obtain $\mathrm{CO}$ and $\mathrm{CO}_{2}$ mixing ratios in agreement with observations is only $20 \mathrm{yr}$. In both of these cases, although the stratospheric $\mathrm{CO}_{2}$ mixing ratio agrees with the value that Orton et al. (2014b) consider their best fit, the column densities are a factor of 2 below the Spitzer measurements.

\section{7. $\mathrm{HCN}$ as diagnostic of $\mathrm{CO}$ origin}

The Shoemaker-Levy 9 impact on Jupiter in July 1994 evidenced the delivery of other minor species of cometary origin in addition to CO (Lellouch et al. 1995). Bézard et al. (1997) was able to detect emission from hydrogen cyanide over all the impact sites they observed with the NASA Infrared Telescope Facility. The total mass of HCN delivered by the SL9 impact was $1.1 \pm 0.4 \times 10^{13} \mathrm{~g}$. On the other hand, the total mass of $\mathrm{CO}$ was estimated to be $1.5 \pm 0.6 \times 10^{15} \mathrm{~g}$ (Lellouch et al. 1997). This gives a mass ratio $\mathrm{CO} / \mathrm{HCN} \sim 100$ for the material delivered by the cometary impact. 
Table 5. Fit (Y/N) to current $\mathrm{H}_{2} \mathrm{O}, \mathrm{CO}$, and $\mathrm{CO}_{2}$ observations with models developed in this work.

\begin{tabular}{lccc}
\hline \hline & $\mathrm{H}_{2} \mathrm{O}$ & $\mathrm{CO}$ & $\mathrm{CO}_{2}$ \\
\hline Steady source $^{a}$ & $\mathrm{Y}$ & $\mathrm{Y}$ & $\mathrm{Y}$ \\
& $6.0 \times 10^{4} \mathrm{~cm}^{-2} \mathrm{~s}^{-1}$ & $2.7 \times 10^{5} \mathrm{~cm}^{-2} \mathrm{~s}^{-1}$ & $4.5 \times 10^{3} \mathrm{~cm}^{-2} \mathrm{~s}^{-1}$ \\
$\begin{array}{l}\text { Cometary impact }^{b} \\
\left(D, t_{\text {impact }}\right)\end{array}$ & $\mathrm{N}$ & $\mathrm{Y}$ & $\mathrm{N}$ \\
$\begin{array}{l}\text { Combined source } \\
\text { Influx }\end{array}$ & $\mathrm{Y}$ & $(2 \mathrm{~km}, 629 \mathrm{yr})^{c}$ & $\mathrm{Y}$ \\
& $6.0 \times 10^{4} \mathrm{~cm}^{-2} \mathrm{~s}^{-1}$ & $(2 \mathrm{~km}, 629 \mathrm{yr})^{c}$ & \\
Influx / $\left(D, t_{\text {impact }}\right)$ & $6.0 \times 10^{4} \mathrm{~cm}^{-2} \mathrm{~s}^{-1}$ & $(2 \mathrm{~km}, 629 \mathrm{yr})^{c}$ & $4.5 \times 10^{3} \mathrm{~cm}^{-2} \mathrm{~s}^{-1}$ \\
Influx $_{\left(D, t_{\text {impact }}\right)^{d}}$ & $6.0 \times 10^{4} \mathrm{~cm}^{-2} \mathrm{~s}^{-1}$ & $\left(2.45 \times 10^{4} \mathrm{~cm}^{-2} \mathrm{~s}^{-1}\right)^{d}$ & $4.5 \times 10^{3} \mathrm{~cm}^{-2} \mathrm{~s}^{-1}$ \\
& & $\left(2 \mathrm{~km}, 639 \mathrm{yr}^{d}\right.$ & \\
\hline
\end{tabular}

Notes. ${ }^{(a)}$ Steady source due to ice grain ablation with integrated fluxes as indicated. ${ }^{(b)}$ Cometary impact delivering $\mathrm{CO}$ and $\mathrm{H}_{2} \mathrm{O} .{ }^{(c)}$ Impactor size and time of the event listed in Table 4 as case 3 . We note the degeneracy in $(D, t)$ for the cometary impact cases in Table $4 .{ }^{(d)}$ Scenarios in which the oxygen is supplied both by a cometary impact and by ice grain ablation.

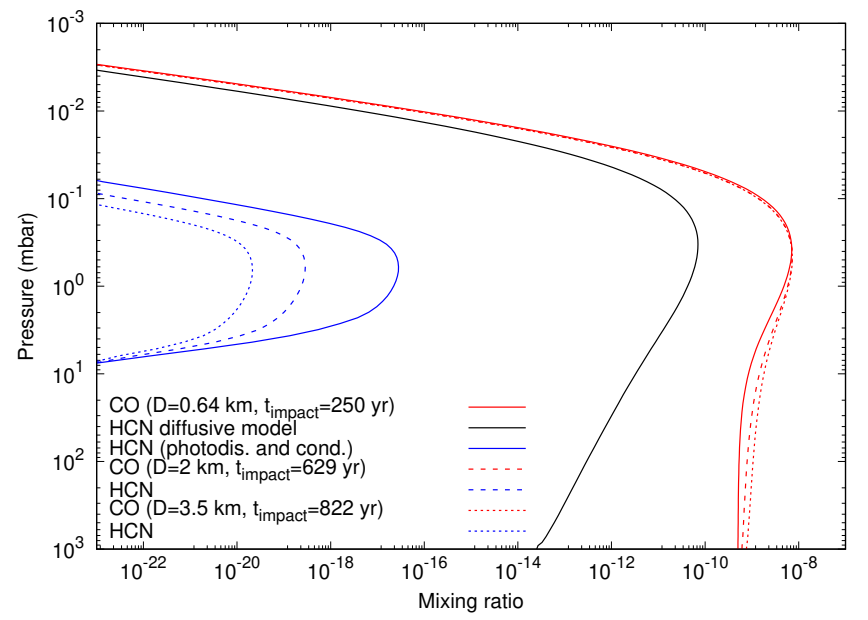

Fig. 11. $\mathrm{CO}$ and $\mathrm{HCN}$ mixing ratio profiles assuming both species are delivered by a cometary impact with parameters $\left(D, t_{\text {impact }}\right)$ as indicated. The resulting $\mathrm{CO}$ profiles match the Herschel observations.

In our modelling, we assume that the hypothetical comet that could have impacted on Uranus injected hydrogen cyanide into the planet's atmosphere as $1 \%$ of the carbon monoxide (in mass) at pressure levels $p \leq 0.1$ mbar. Once in the atmosphere, $\mathrm{HCN}$ is subjected to eddy and molecular diffusion, condensation, and photochemical processes.

As an exploratory work, we first ran a pure diffusive model (hydrogen cyanide does not undergo either photochemistry or condensation) in which an impactor of $0.64 \mathrm{~km}$ diameter hit the planet $250 \mathrm{yr}$ ago (case 0 in Table 4). Figure 11 shows the $\mathrm{CO}$ and $\mathrm{HCN}$ resulting profiles. As expected, carbon monoxide reproduced the Herschel observations in the stratosphere, and the hydrogen cyanide mixing ratio is $\sim 100$ times lower than that of CO: $q_{\mathrm{HCN}} \sim 5.0 \times 10^{-11}$. Since the molecular mass of $\mathrm{CO}$ and $\mathrm{HCN}$ are very similar, diffusive separation acts similarly on both species at low pressures. On the other hand, at higher pressures, carbon monoxide and hydrogen cyanide mixing ratio profiles considerably differ due to the lower boundary condition imposed on $\mathrm{HCN}$ (maximum downward flux) and on $\mathrm{CO}$ (constant mixing ratio at $\left.5.0 \times 10^{-10}\right)$.
Aiming for a more realistic model, we also considered that hydrogen cyanide suffers photodissociation and condensation, whereas chemical recycling is not considered in this work. Therefore, in this work HCN is irreversibly lost by photodissociation in the upper atmosphere and condensation in the 140-2 mbar region where the abundance drastically decreases to very low mixing ratios. For three different cometary impact scenarios (cases 0, 2, and 3 in Table 4), the model results are shown in Fig. 11. The hydrogen cyanide mixing ratio is $\leq 3.0 \times$ $10^{-17}$ at the 0.5 mbar pressure level, undetectable from ground with ALMA (T. Cavalié, priv. comm.). More recent impacts (and thus, smaller impactors than the ones in Table 4) give rise to a higher concentration of hydrogen cyanide in the stratosphere, whereas older events produce broader $\mathrm{HCN}$ profiles peaking at much lower mixing ratio values.

To assess the importance of the chemical production of $\mathrm{HCN}$, we have studied likely sources involving nitrogen species such as $\mathrm{N}_{2}$ and $\mathrm{NH}_{3}$. For this, we ran a thermochemical model with the (p,T) profile from Fig. 3 in Cavalié et al. (2014) and the same $\mathrm{O} / \mathrm{H}$ and $\mathrm{C} / \mathrm{H}$ values (501 and 18 times the solar value), and $\mathrm{N} / \mathrm{H}$ solar value. The obtained $\mathrm{NH}_{3}$ molar fraction is $\sim 10^{-4}$ from $\sim 10^{4}$ bar up to 3.2 bar. Ammonia condenses considerably below the tropopause, thus it cannot initiate gaseous chemistry above this level. The $\mathrm{N}_{2}$ molar fraction smoothly decreases with decreasing pressure from $\sim 10^{-7}$ at $\sim 10^{4}$ bar to $\sim 10^{-16}$ at 80 bar. For $K_{z z}=10^{8} \mathrm{~cm}^{2} \mathrm{~s}^{-1}$ as in Cavalié et al. (2014), the $\mathrm{N}_{2}$ quenching level might be between 2000 and 3000 bar, hence at lower pressure levels, molecular nitrogen should have a fairly (and low) constant mixing ratio of $\sim 10^{-8}$. However, Fegley \& Prinn (1986) concluded that their thermochemical equilibrium calculations (for a model enriched 500 times relative to solar abundances) predict that $\mathrm{N}_{2}$ is the most abundant non-equilibrium trace gas which can be mixed upward from the deep atmosphere of Uranus yielding $130 \mathrm{ppmv}\left(1.3 \times 10^{-4}\right)$ for an eddy diffusion coefficient in the range $10^{7}-10^{8} \mathrm{~cm}^{2} \mathrm{~s}^{-1}$. Conrath et al. (1993) estimated $\mathrm{N}_{2}$ could be as high as $0.3-0.6 \%$ in Neptune and thus, similar to Uranus if the He mixing ratio is 0.15 for both planets. For an enrichment of nitrogen 500 times the solar value and $K_{z z}=10^{8} \mathrm{~cm}^{2} \mathrm{~s}^{-1}$, our thermochemical model predicts a molecular nitrogen mixing ratio ranging from $\sim 3 \%$ at $p>700$ mbar and $\sim 7 \%$ at lower pressures. In either case, it might well be possible that galactic cosmic rays (GCR) that impact on $\mathrm{N}_{2}$ 
can initiate an effective nitrogen chemistry (see e.g. Table II in Lellouch et al. 1994) able to steadily produce HCN. We leave the inclusion of nitrogen chemistry in the Uranus atmosphere for a future paper.

A comparison of the likely $\mathrm{HCN}$ abundance in the Uranus atmosphere and that detected in the atmospheres of Neptune and Jupiter is also very instructive. In Neptune's atmosphere, in addition to the cometary impact delivering $\mathrm{HCN}$, there might be chemical sources forming HCN which would allow for a higher stratospheric abundance versus the scenario where $\mathrm{HCN}$ only originates from a cometary impact and is lost by photolysis and condensation. Lellouch et al. (1994, 2005) took into account chemical formation processes for $\mathrm{HCN}$ : nitrogen atoms escaping Triton and entering Neptune's upper atmosphere, and $\mathrm{N}_{2}$ dissociation by galactic cosmic ray impact reaching deep atmospheric levels. In addition to this, Neptune orbits the Sun at $~ 30$ AU (versus $\sim 19$ AU for Uranus) causing a lower radiation flux reaching the planet. Additionally, the methane abundance is two orders of magnitude higher in Neptune's atmosphere than in the Uranus atmosphere; the homopause in Neptune's atmosphere is at lower pressure levels than in that of Uranus; methane and the $C_{2}, C_{3}$, and $\mathrm{C}_{4}$ hydrocarbons can absorb most of the UV solar radiation high in the stratosphere shielding the photolysis of other very minor species. As a conclusion, $\mathrm{HCN}$ photodissociation on Neptune proceeds at a much slower rate than on Uranus.

Regarding HCN in Jupiter's atmosphere, we note that although Jupiter receives a much higher UV solar flux (orbit of the planet at 5.2 AU from the Sun), the methane and hydrocarbon abundances are considerably higher at Jupiter than at Uranus, and the Jovian hompause is at $\sim 10^{-4}$ mbar at much higher levels than on Uranus. Thus, the $\mathrm{HCN}$ photochemical lifetime in Jupiter's atmosphere is much longer than in the Uranus atmosphere.

This work leads us to conclude that, unless HCN is chemically formed, once produced by the cometary impact, it is irreversibly destroyed resulting in barely detectable abundances in the stratosphere. A larger comet nucleus impacting the planet (i.e. more $\mathrm{HCN}$ injected in the atmosphere) does not alleviate the problem as the evolution time has to be longer to match the measured $\mathrm{CO}$ giving rise to a drastic depletion of $\mathrm{HCN}$.

Detecting and measuring the HCN abundance could help to provide a further constraint on the origin of carbon monoxide in the Uranus atmosphere. A non-detection, placing an upper limit on the HCN abundance, would be also valuable to constrain $\left(D, t_{\text {impact }}\right)$. Hence, the hydrogen cyanide abundance predicted in this work is a worst-case scenario and it has to be regarded with caution.

\section{Conclusions}

The different scenarios analysed in this work that allow for a good match to current observations of water, carbon monoxide, and carbon dioxide in the Uranus atmosphere are shown in Table 5.

The available observations of $\mathrm{H}_{2} \mathrm{O}, \mathrm{CO}$, and $\mathrm{CO}_{2}$ can be fit by assuming that these oxygen-bearing species are solely produced by ice grain ablation, as shown in Moses \& Poppe (2017), with an influx rate of $3.75 \times 10^{5} \mathrm{~cm}^{-2} \mathrm{~s}^{-1}$ (see first row in Table 5).

Developing time-dependent photochemical models in which the currently observed atmospheric $\mathrm{CO}$ is delivered by a cometary impact alone, we were able to constrain the size (in $\mathrm{km}$ ) of the impact and when it could have taken place. Our results indicate that impactors $D \leq 3.5 \mathrm{~km}$ ocurring $t_{\text {impact }} \leq 822 \mathrm{yr}$ give rise to $\mathrm{CO}$ in agreement with observations, and are compatible with the impact rates at Uranus shown in Zahnle et al. (2003). Whereas the cometary $\mathrm{CO}$ allows us to reproduce the observations, the cometary $\mathrm{H}_{2} \mathrm{O}$ renders stratospheric abundances much lower than ISO data due to a much shorter lifetime than that of $\mathrm{CO}$, being necessary a steady influx of water to match ISO observations. Similarly, the scenario of $\mathrm{CO}$ and $\mathrm{H}_{2} \mathrm{O}$ originated from an impact (mass ratio of 90:10) fails to chemically produce enough $\mathrm{CO}_{2}$. A combined source of external oxygen (i.e. $\mathrm{CO}$ due to a cometary impact and/or ice grain ablation, and $\mathrm{H}_{2} \mathrm{O}$ and $\mathrm{CO}_{2}$ supplied from ice grain ablation) provides a good fit to the measured abundances of these three species. Current carbon monoxide observations (Cavalié et al. 2014) do no allow us to discriminate between the three analysed scenarios, namely oxygen-bearing species supplied by cometary origin, by ice grain ablation, or both. The $\mathrm{CO}$ vertical mixing ratio profile shows a very different shape when due to the ablation of ice grains, to cometary impact, or to a combination of the two (see Fig. 17 in Moses \& Poppe 2017, and Figs. 8 and 9 in this work). Regarding water and carbon dioxide, we can conclude that a cometary impact is not the only cause of the current abundance of these species in the Uranus atmosphere; instead, a steady source has to be invoked.

Ideally, observations whose analysis retrieve vertical profiles could provide the answer to the open question of the oxygen origin in the Uranus atmosphere. Another approach to shed light on this open question could be the search for trace species, for example HCN, as the aftermath of the collision of a comet on Uranus. A simulation of the temporal evolution of cometary $\mathrm{HCN}$ indicates that, once deposited at $p \leq 0.1 \mathrm{mbar}$ and in the absence of nitrogen chemistry, its photodissociation and condensation decrease its abundance to almost undetectable levels by current ground-based facilities as ALMA. Chemical hydrogen cyanide recycling initiated by GCR impact on $\mathrm{N}_{2}$ could give rise to much higher, and thus detectable, HCN stratospheric abundance.

Acknowledgements. This research has been supported by the Spanish Ministerio de Economía y Competitividad under contracts ESP2014-54062-R and ESP 2016-76076-R. L.M.L. wishes to express her gratitude to the International Space Science Institute (at Bern, Switzerland) for supporting her research in the framework of the Visiting Science Program. M.L. acknowledges the Agencia Estatal de Investigación for the BES-2015-074542 fellowship co-funded by the Fondo Social Europeo. We are very grateful to the reviewer, Dr T. Cavalié, for the detailed comments which have considerably improved the manuscript.

\section{References}

Bézard, B., Griffith, C. A., Kelly, D. M., et al. 1997, Icarus, 125, 94 Borysow, A., \& Frommhold, L. 1986, ApJ, 304, 849

Borysow, J., Trafton, L., Frommhold, L., \& Birnbaum, G. 1985, ApJ, 296, 644 Borysow, J., Frommhold, L., \& Birnbaum, G. 1988, ApJ, 326, 509 Cavalié, T., Billebaud, F., Dobrijevic, M., et al. 2009, Icarus, 203, 531 Cavalié, T., Hartogh, P., Billebaud, F., et al. 2010, A\&A, 510, A88 Cavalié, T., Feuchtgruber, H., Lellouch, E., et al. 2013, A\&A, 553, A21 Cavalié, T., Moreno, R., Lellouch, E., et al. 2014, A\&A, 562, A33 Conrath, B., Gautier, D., Hanel, R., Lindal, G., \& Marten, A. 1987, J. Geophys. Res., 92, 15003

Conrath, B. J., Gautier, D., Owen, T. C., \& Samuelson, R. E. 1993, Icarus, 101, 168

Fegley, Jr., B., \& Prinn, R. G. 1986, ApJ, 307, 852

Feuchtgruber, H., Lellouch, E., de Graauw, T., et al. 1997, Nature, 389, 159

Fletcher, L. N., Swinyard, B., Salji, C., et al. 2012, A\&A, 539, A44

González, A., Hartogh, P., \& Lara, L. M. 2011, Adv. Geosci., 25, 209

Krasnopolsky, V. A. 2009, Icarus, 201, 226

Lara, L. M., Lellouch, E., González, M., Moreno, R., \& Rengel, M. 2014, A\&A, 566, A143

Lavvas, P. P., Coustenis, A., \& Vardavas, I. M. 2008a, Planet. Space Sci., 56, 27 Lavvas, P. P., Coustenis, A., \& Vardavas, I. M. 2008b, Planet. Space Sci., 56, 67 Lellouch, E., Romani, P. N., \& Rosenqvist, J. 1994, Icarus, 108, 112 
L. M. Lara et al.: Time-dependent Uranus photochemistry and oxygen source

Lellouch, E., Paubert, G., Moreno, R., et al. 1995, Nature, 373, 592

Lellouch, E., Bézard, B., Moreno, R., et al. 1997, Planet. Space Sci., 45, 1203

Lellouch, E., Bézard, B., Moses, J. I., et al. 2002, Icarus, 159, 112

Lellouch, E., Moreno, R., \& Paubert, G. 2005, A\&A, 430, L37

Lellouch, E., Hartogh, P., Feuchtgruber, H., et al. 2010, A\&A, 518, L152

Lellouch, E., Moreno, R., Orton, G. S., et al. 2015, A\&A, 579, A121

Lindal, G. F., Lyons, J. R., Sweetnam, D. N., et al. 1987, J. Geophys. Res., 92, 14987

Mantz, A. W., Malathy Devi, V., Chris Benner, D., et al. 2005, J. Mol. Struct., 742,99

Marti, J., \& Mauersberger, K. 1993, Geophys. Res. Lett., 20, 363

Mauersberger, K., \& Krankowsky, D. 2003, Geophys. Res. Lett., 30, 1121

Moreno, R., Marten, A., Biraud, Y., et al. 2001, Planet. Space Sci., 49, 473

Moreno, R., Lellouch, E., Lara, L. M., et al. 2012, Icarus, 221, 753

Moreno, R., Lellouch, E., Cavalié, T., \& Moullet, A. 2017, A\&A, 608, L5
Moses, J. I., \& Poppe, A. R. 2017, Icarus, 297, 33

Moses, J. I., Bézard, B., Lellouch, E., et al. 2000a, Icarus, 143, 244

Moses, J. I., Lellouch, E., Bézard, B., et al. 2000b, Icarus, 145, 166

Moses, J. I., Fouchet, T., Bézard, B., et al. 2005, J. Geophys. Res. Planets, 110, 8001

Orton, G. S., Fletcher, L. N., Moses, J. I., et al. 2014a, Icarus, 243, 494

Orton, G. S., Moses, J. I., Fletcher, L. N., et al. 2014b, Icarus, 243, 471

Pickett, H. M., Poynter, R. L., Cohen, E. A., et al. 1998, J. Quant. Spectr. Rad. Transf., 60, 883

Poppe, A. R. 2016, Icarus, 264, 369

Sung, K. 2004, J. Quant. Spectr. Rad. Transf., 83, 445

Teanby, N. A., \& Irwin, P. G. J. 2013, ApJ, 775, L49

Wakelam, V., Herbst, E., Loison, J.-C., et al. 2012, ApJS, 199, 21

Wu, C. Y. R., Chen, F. Z., \& Judge, D. L. 2004, J. Geophys. Res. Planets, 109, E07S15

Zahnle, K., Schenk, P., Levison, H., \& Dones, L. 2003, Icarus, 163, 263 


\section{Appendix A: List of chemical reactions}

Table A.1. $\mathrm{C}-\mathrm{H}-\mathrm{O}$ reactions.

\begin{tabular}{|c|c|}
\hline Reaction & Rate coefficient \\
\hline $\mathrm{O}\left({ }^{3} \mathrm{P}\right)+\mathrm{H}_{2} \rightarrow \mathrm{OH}+\mathrm{H}$ & $k_{159}=8.49 \times 10^{-20} T^{2.67} \exp (-3160.0 / T)$ \\
\hline $\mathrm{O}\left({ }^{3} \mathrm{P}\right)+\mathrm{CH}_{3} \rightarrow \mathrm{H}_{2} \mathrm{CO}+\mathrm{H}$ & $k_{162 b}=1.4 \times 10^{-10}$ \\
\hline $\mathrm{O}\left({ }^{3} \mathrm{P}\right)+\mathrm{C}_{2} \mathrm{H} \rightarrow \mathrm{CO}+\mathrm{CH}$ & $k_{164}=1.7 \times 10^{-11}$ \\
\hline $\mathrm{O}\left({ }^{3} \mathrm{P}\right)+\mathrm{C}_{2} \mathrm{H}_{2} \rightarrow \mathrm{CO}+{ }^{3} \mathrm{CH}_{2}$ & $k_{165 a}=1.5 \times 10^{-11} * \exp (-1600.0 / T)$ \\
\hline $\mathrm{O}\left({ }^{3} \mathrm{P}\right)+\mathrm{C}_{2} \mathrm{H}_{2} \rightarrow \mathrm{HCCO}+\mathrm{H}$ & $k_{165 b}=5 \times 10^{-11} * \exp (-1600.0 / T)$ \\
\hline $\mathrm{O}\left({ }^{3} \mathrm{P}\right)+\mathrm{C}_{2} \mathrm{H}_{3} \rightarrow \mathrm{OH}+\mathrm{C}_{2} \mathrm{H}_{2}$ & $k_{166 a}=1.25 \times 10^{-11}$ \\
\hline $\mathrm{O}\left({ }^{3} \mathrm{P}\right)+\mathrm{C}_{2} \mathrm{H}_{3} \rightarrow \mathrm{CO}+\mathrm{CH}_{3}$ & $k_{166 b}=1.25 \times 10^{-11}$ \\
\hline $\mathrm{O}\left({ }^{3} \mathrm{P}\right)+\mathrm{C}_{2} \mathrm{H}_{3} \rightarrow \mathrm{HCO}+{ }^{3} \mathrm{CH}_{2}$ & $k_{166 c}=1.25 \times 10^{-11}$ \\
\hline $\mathrm{O}\left({ }^{3} \mathrm{P}\right)+\mathrm{C}_{2} \mathrm{H}_{3} \rightarrow \mathrm{CH}_{2} \mathrm{CO}+\mathrm{H}$ & $k_{166 d}=1.25 \times 10^{-11}$ \\
\hline $\mathrm{O}\left({ }^{3} \mathrm{P}\right)+\mathrm{C}_{2} \mathrm{H}_{4} \rightarrow \mathrm{HCO}+\mathrm{CH}_{3}$ & $k_{167 a}=3.45 \times 10^{-18} T^{2.08}$ \\
\hline $\mathrm{O}\left({ }^{3} \mathrm{P}\right)+\mathrm{C}_{2} \mathrm{H}_{4} \rightarrow \mathrm{H}_{2} \mathrm{CO}+{ }^{3} \mathrm{CH}_{2}$ & $k_{167 b}=1.5 \times 10^{-19} T^{2.08}$ \\
\hline $\mathrm{O}\left({ }^{3} \mathrm{P}\right)+\mathrm{C}_{2} \mathrm{H}_{4} \rightarrow \mathrm{CH}_{2} \mathrm{CO}+\mathrm{H}_{2}$ & $k_{167 c}=1.5 \times 10^{-19} T^{2.08}$ \\
\hline $\mathrm{O}\left({ }^{3} \mathrm{P}\right)+\mathrm{C}_{2} \mathrm{H}_{4} \rightarrow \mathrm{CH}_{3} \mathrm{CO}+\mathrm{H}$ & $k_{167 d}=2.0 \times 10^{-18} T^{2.08}$ \\
\hline $\mathrm{O}\left({ }^{3} \mathrm{P}\right)+\mathrm{C}_{2} \mathrm{H}_{5} \rightarrow \mathrm{H}_{2} \mathrm{CO}+\mathrm{CH}_{3}$ & $k_{168 a}=1.7 \times 10^{-11}$ \\
\hline $\mathrm{O}\left({ }^{3} \mathrm{P}\right)+\mathrm{C}_{2} \mathrm{H}_{5} \rightarrow \mathrm{CH}_{3} \mathrm{CHO}+\mathrm{H}$ & $k_{168 b}=8.3 \times 10^{-11}$ \\
\hline $\mathrm{O}\left({ }^{3} \mathrm{P}\right)+\mathrm{OH} \rightarrow \mathrm{O}_{2}+\mathrm{H}$ & $k_{171}=2.3 \times 10^{-11} \exp (110.0 / T)$ \\
\hline $\mathrm{O}\left({ }^{3} \mathrm{P}\right)+\mathrm{CO}+\mathrm{M} \rightarrow \mathrm{CO}_{2}+\mathrm{M}$ & $k_{0,172}=6.5 \times 10^{-33} \exp (-2180.0 / T)$ \\
\hline $\mathrm{O}\left({ }^{3} \mathrm{P}\right)+\mathrm{HCO} \rightarrow \mathrm{CO}_{2}+\mathrm{H}$ & $\begin{array}{l}k_{\infty, 172}=2.00 \times 10 \\
k_{173 b}=5.0 \times 10^{-11}\end{array}$ \\
\hline $\mathrm{O}\left({ }^{3} \mathrm{P}\right)+\mathrm{H}_{2} \mathrm{CO} \rightarrow \mathrm{HCO}+\mathrm{OH}$ & $k_{174}=6.9 \times 10^{-13} T^{0.57} \exp (-1390.0 / T)$ \\
\hline $\mathrm{O}\left({ }^{3} \mathrm{P}\right)+\mathrm{CH}_{3} \mathrm{O} \rightarrow \mathrm{O}_{2}+\mathrm{CH}_{3}$ & $k_{176 b}=3.55 \times 10^{-11} \exp (-239.0 / T)$ \\
\hline $\mathrm{O}\left({ }^{3} \mathrm{P}\right)+\mathrm{CH}_{3} \mathrm{OH} \rightarrow \mathrm{CH}_{2} \mathrm{OH}+\mathrm{OH}$ & $k_{177 a}=3.2 \times 10^{-19} T^{2.5} \exp (-1550.0 / T)$ \\
\hline $\mathrm{O}\left({ }^{3} \mathrm{P}\right)+\mathrm{CH}_{3} \mathrm{OH} \rightarrow \mathrm{CH}_{3} \mathrm{O}+\mathrm{OH}$ & $k_{177 b}=3.2 \times 10^{-19} T^{2.5} \exp (-1550.0 / T)$ \\
\hline $\mathrm{O}\left({ }^{3} \mathrm{P}\right)+\mathrm{HCCO} \rightarrow \mathrm{CO}+\mathrm{CO}+\mathrm{H}$ & $k_{178}=1.6 \times 10^{-10}$ \\
\hline $\mathrm{O}\left({ }^{3} \mathrm{P}\right)+\mathrm{CH}_{2} \mathrm{CO} \rightarrow \mathrm{HCO}+\mathrm{CO}+\mathrm{H}$ & $k_{179 a}=1.3 \times 10^{-12} \exp (-680.0 / T)$ \\
\hline $\mathrm{O}\left({ }^{3} \mathrm{P}\right)+\mathrm{CH}_{2} \mathrm{CO} \rightarrow \mathrm{H}_{2} \mathrm{CO}+\mathrm{CO}$ & $k_{179 c}=1.3 \times 10^{-12} \exp (-680.0 / T)$ \\
\hline $\mathrm{O}\left({ }^{3} \mathrm{P}\right)+\mathrm{CH}_{3} \mathrm{CO} \rightarrow \mathrm{CO}_{2}+\mathrm{CH}_{3}$ & $k_{180 b}=2.4 \times 10^{-10}$ \\
\hline $\mathrm{O}\left({ }^{3} \mathrm{P}\right)+\mathrm{CH}_{3} \mathrm{CHO} \rightarrow \mathrm{CH}_{3} \mathrm{CO}+\mathrm{OH}$ & $k_{181}=1.8 \times 10^{-11} \exp (-1100.0 / T)$ \\
\hline $\mathrm{O}\left({ }^{3} \mathrm{P}\right)+\mathrm{C}_{2} \mathrm{H}_{4} \mathrm{OH} \rightarrow \mathrm{CH}_{3} \mathrm{CHO}+\mathrm{OH}$ & $k_{182}=1.5 \times 10^{-10}$ \\
\hline $\mathrm{O}\left({ }^{1} \mathrm{D}\right) \rightarrow \mathrm{O}\left({ }^{3} \mathrm{P}\right)$ & $6.7 \times 10^{-3}$ \\
\hline $\mathrm{O}\left({ }^{1} \mathrm{D}\right)+\mathrm{H}_{2} \rightarrow \mathrm{OH}+\mathrm{H}$ & $k_{183}=1.5 \times 10^{-10}$ \\
\hline $\mathrm{O}\left({ }^{1} \mathrm{D}\right)+\mathrm{CH}_{4} \rightarrow \mathrm{OH}+\mathrm{CH}_{3}$ & $k_{184 a}=1.35 \times 10^{-10}$ \\
\hline $\mathrm{O}\left({ }^{1} \mathrm{D}\right)+\mathrm{CH}_{4} \rightarrow \mathrm{H}_{2} \mathrm{CO}+\mathrm{H}_{2}$ & $k_{184 b}=1.5 \times 10^{-11}$ \\
\hline $\mathrm{O}\left({ }^{1} \mathrm{D}\right)+\mathrm{H}_{2} \mathrm{O} \rightarrow \mathrm{OH}+\mathrm{OH}$ & $k_{185}=2.1 \times 10^{-10}$ \\
\hline $\mathrm{O}\left({ }^{1} \mathrm{D}\right)+\mathrm{CO}_{2} \rightarrow \mathrm{CO}_{2}+\mathrm{O}\left({ }^{3} \mathrm{P}\right)$ & $k_{186}=7.4 \times 10^{-11} \exp (120.0 / T)$ \\
\hline \multirow[t]{2}{*}{$\mathrm{OH}+\mathrm{H}+\mathrm{M} \rightarrow \mathrm{H}_{2} \mathrm{O}+\mathrm{M}$} & $k_{0,187}=6.1 \times 10^{-26} * T^{-2.0}$ \\
\hline & $k_{\infty, 187}=2.69 \times 10^{-10} \exp (-75.0 / T)$ \\
\hline $\mathrm{OH}+\mathrm{H}_{2} \rightarrow \mathrm{H}_{2} \mathrm{O}+\mathrm{H}$ & $k_{188}=7.7 \times 10^{-12} \exp (-2100.0 / T)$ \\
\hline $\mathrm{OH}+\mathrm{CH}_{3} \rightarrow \mathrm{H}_{2} \mathrm{O}+{ }^{1} \mathrm{CH}_{2}$ & $k_{190 a}=1.0 \times 10^{-12}$ \\
\hline $\mathrm{OH}+\mathrm{CH}_{3}+\mathrm{M} \rightarrow \mathrm{CH}_{3} \mathrm{OH}+\mathrm{M}$ & $k_{0,191}=6.4 \times 10^{-29} \exp (1033.0 / T)$ \\
\hline & $k_{\infty, 191}=1.44 \times 10^{-10} T^{0.1}$ \\
\hline $\mathrm{OH}+\mathrm{CH}_{4} \rightarrow \mathrm{H}_{2} \mathrm{O}+\mathrm{CH}_{3}$ & $k_{192}=3.9 \times 10^{-12} \exp (-1885.0 / T)$ \\
\hline $\mathrm{OH}+\mathrm{C}_{2} \mathrm{H} \rightarrow \mathrm{O}\left({ }^{3} \mathrm{P}\right)+\mathrm{C}_{2} \mathrm{H}_{2}$ & $k_{193 a}=3.0 \times 10^{-11}$ \\
\hline \multirow[t]{2}{*}{$\mathrm{OH}+\mathrm{C}_{2} \mathrm{H}_{2}+\mathrm{M} \rightarrow \mathrm{CH}_{3} \mathrm{CO}+\mathrm{M}$} & $k_{0,194 a}=2.6 \times 10^{-26} T^{-1.5}$ \\
\hline & $k_{\infty, 194 a}=1.0 \times 10^{-17} T^{2.0}$ \\
\hline $\mathrm{OH}+\mathrm{C}_{2} \mathrm{H}_{3} \rightarrow \mathrm{H}_{2} \mathrm{O}+\mathrm{C}_{2} \mathrm{H}_{2}$ & $k_{195}=5.0 \times 10^{-11}$ \\
\hline
\end{tabular}

Here we list the chemical reactions coupling oxygen species and hydrocarbons. The models were also run considering the hydrocarbon-hydrocarbon reactions not listed here. The numbering of the reactions reflects the complete set of considered reactions, listing here only those involving oxygen species. All values are quoted in the $\mathrm{cm}$ s system. Three-body reaction rates are computed according to the expression $k=\left(k_{0} k_{\infty}\right) /\left(k_{0} M+\right.$ $k_{\infty}$ ), where $M$ denotes the total number density. 
Table A.1. continued.

\begin{tabular}{|c|c|}
\hline Reaction & Rate coefficient \\
\hline $\mathrm{OH}+\mathrm{C}_{2} \mathrm{H}_{4}+\mathrm{M} \rightarrow \mathrm{C}_{2} \mathrm{H}_{4} \mathrm{OH}+\mathrm{M}$ & $\begin{array}{l}k_{0,197}=3.34 \times 10^{-21} T^{-3.1} \\
k_{\infty, 197}=9.0 \times 10^{-12}\end{array}$ \\
\hline $\mathrm{OH}+\mathrm{C}_{2} \mathrm{H}_{5} \rightarrow \mathrm{O}\left({ }^{3} \mathrm{P}\right)+\mathrm{C}_{2} \mathrm{H}_{6}$ & $k_{198 a}=1.66 \times 10^{-40} T^{8.8} \exp (-250.0 / T)$ \\
\hline $\mathrm{OH}+\mathrm{C}_{2} \mathrm{H}_{5} \rightarrow \mathrm{H}_{2} \mathrm{O}+\mathrm{C}_{2} \mathrm{H}_{4}$ & $k_{198 b}=4.0 \times 10^{-11}$ \\
\hline $\mathrm{OH}+\mathrm{C}_{2} \mathrm{H}_{6} \rightarrow \mathrm{H}_{2} \mathrm{O}+\mathrm{C}_{2} \mathrm{H}_{5}$ & $k_{199}=7.8 \times 10^{-12} \exp (-1020.0 / T)$ \\
\hline $\mathrm{OH}+\mathrm{OH} \rightarrow \mathrm{H}_{2} \mathrm{O}+\mathrm{O}\left({ }^{3} \mathrm{P}\right)$ & $k_{200}=4.2 \times 10^{-12} \exp (-240.0 / T)$ \\
\hline $\mathrm{OH}+\mathrm{CO} \rightarrow \mathrm{CO}_{2}+\mathrm{H}$ & $k_{201}=2.86 \times 10^{-13} \exp (-176 . / T)$ \\
\hline $\mathrm{OH}+\mathrm{HCO} \rightarrow \mathrm{CO}+\mathrm{H}_{2} \mathrm{O}$ & $k_{202}=1.7 \times 10^{-10}$ \\
\hline $\mathrm{OH}+\mathrm{H}_{2} \mathrm{CO} \rightarrow \mathrm{HCO}+\mathrm{H}_{2} \mathrm{O}$ & $k_{203}=8.8 \times 10^{-12} \exp (25.0 / T)$ \\
\hline $\mathrm{OH}+\mathrm{CH}_{3} \mathrm{OH} \rightarrow \mathrm{CH}_{2} \mathrm{OH}+\mathrm{H}_{2} \mathrm{O}$ & $k_{206 a}=5.0 \times 10^{-12} \exp (-600.0 / T)$ \\
\hline $\mathrm{OH}+\mathrm{CH}_{3} \mathrm{OH} \rightarrow \mathrm{CH}_{3} \mathrm{O}+\mathrm{H}_{2} \mathrm{O}$ & $k_{206 b}=1.68 \times 10^{-12} \exp (-600.0 / T)$ \\
\hline $\mathrm{OH}+\mathrm{CH}_{2} \mathrm{CO} \rightarrow \mathrm{H}_{2} \mathrm{CO}+\mathrm{HCO}$ & $k_{207 a}=7.0 \times 10^{-12}$ \\
\hline $\mathrm{OH}+\mathrm{CH}_{2} \mathrm{CO} \rightarrow \mathrm{CH}_{2} \mathrm{OH}+\mathrm{CO}$ & $k_{207 b}=1.0 \times 10^{-11}$ \\
\hline $\mathrm{OH}+\mathrm{CH}_{3} \mathrm{CHO} \rightarrow \mathrm{CH}_{3} \mathrm{CO}+\mathrm{H}_{2} \mathrm{O}$ & $k_{209}=5.6 \times 10^{-12} \exp (310.0 / T)$ \\
\hline \multirow[t]{2}{*}{$\mathrm{H}_{2} \mathrm{O}+\mathrm{CH}+\mathrm{M} \rightarrow \mathrm{CH}_{2} \mathrm{OH}+\mathrm{M}$} & $k_{0,210}=1.0 \times 10^{-31}$ \\
\hline & $k_{\infty, 210}=9.49 \times 10^{-12} \exp (380.0 / T)$ \\
\hline \multirow[t]{2}{*}{$\mathrm{H}_{2} \mathrm{O}+{ }^{1} \mathrm{CH}_{2}+\mathrm{M} \rightarrow \mathrm{CH}_{3} \mathrm{OH}+\mathrm{M}$} & $k_{0,212}=1.0 \times 10^{-26}$ \\
\hline & $k_{\infty, 212}=2.67 \times 10^{-9} T^{-0.7}$ \\
\hline \multirow{2}{*}{$\mathrm{CO}+\mathrm{H}+\mathrm{M} \rightarrow \mathrm{HCO}+\mathrm{M}$} & $k_{0,213}=1.4 \times 10^{-34} \exp (-100.0 / T)$ \\
\hline & $k_{\infty, 213}=1.96 \times 10^{-13} \exp (-1366.0 / T)$ \\
\hline \multirow[t]{2}{*}{$\mathrm{CO}+\mathrm{CH}_{3}+\mathrm{M} \rightarrow \mathrm{CH}_{3} \mathrm{CO}+\mathrm{M}$} & $k_{0,215}=1.26 \times 10^{-33} \exp (-1636.0 / T)$ \\
\hline & $k_{\infty, 215}=2.63 \times 10^{-13} \exp (-3007.0 / T)$ \\
\hline $\mathrm{HCO}+\mathrm{H} \rightarrow \mathrm{CO}+\mathrm{H}_{2}$ & $k_{217}=1.5 \times 10^{-10}$ \\
\hline $\mathrm{HCO}+{ }^{3} \mathrm{CH}_{2} \rightarrow \mathrm{CO}+\mathrm{CH}_{3}$ & $k_{218}=3.0 \times 10^{-11}$ \\
\hline $\mathrm{HCO}+\mathrm{CH}_{3} \rightarrow \mathrm{CO}+\mathrm{CH}_{4}$ & $k_{219}=4.4 \times 10^{-11}$ \\
\hline \multirow[t]{2}{*}{$\mathrm{HCO}+\mathrm{CH}_{3}+\mathrm{M} \rightarrow \mathrm{CH}_{3} \mathrm{CHO}+\mathrm{M}$} & $k_{0,220}=1.0 \times 10^{-31}$ \\
\hline & $k_{\infty, 220}=5.0 \times 10^{-11}$ \\
\hline $\mathrm{HCO}+\mathrm{C}_{2} \mathrm{H}_{3} \rightarrow \mathrm{CO}+\mathrm{C}_{2} \mathrm{H}_{4}$ & $k_{222}=1.5 \times 10^{-10}$ \\
\hline $\mathrm{HCO}+\mathrm{C}_{2} \mathrm{H}_{5} \rightarrow \mathrm{CO}+\mathrm{C}_{2} \mathrm{H}_{6}$ & $k_{223}=2.0 \times 10^{-10}$ \\
\hline $\mathrm{HCO}+\mathrm{CH}_{3} \mathrm{O} \rightarrow \mathrm{CH}_{3} \mathrm{OH}+\mathrm{CO}$ & $k_{226}=1.5 \times 10^{-10}$ \\
\hline $\mathrm{HCO}+\mathrm{CH}_{3} \mathrm{CO} \rightarrow \mathrm{CH}_{3} \mathrm{CHO}+\mathrm{CO}$ & $k_{228}=1.5 \times 10^{-11}$ \\
\hline $\mathrm{H}_{2} \mathrm{CO}+\mathrm{H} \rightarrow \mathrm{HCO}+\mathrm{H}_{2}$ & $k_{229}=3.8 \times 10^{-14} T^{1.05} \exp (-1650.0 / T)$ \\
\hline $\mathrm{H}_{2} \mathrm{CO}+\mathrm{CH} \rightarrow \mathrm{CO}+\mathrm{CH}_{3}$ & $k_{230 a}=8.0 \times 10^{-11} \exp (260.0 / T)$ \\
\hline $\mathrm{H}_{2} \mathrm{CO}+\mathrm{CH} \rightarrow \mathrm{CH}_{2} \mathrm{CO}+\mathrm{H}$ & $k_{230 b}=8.0 \times 10^{-11} \exp (260.0 / T)$ \\
\hline $\mathrm{H}_{2} \mathrm{CO}+\mathrm{CH}_{3} \rightarrow \mathrm{HCO}+\mathrm{CH}_{4}$ & $k_{231}=6.8 \times 10^{-12} \exp (-4450.0 / T)$ \\
\hline $\mathrm{CH}_{2} \mathrm{OH}+\mathrm{H} \rightarrow \mathrm{OH}+\mathrm{CH}_{3}$ & $k_{236 a}=1.6 \times 10^{-10}$ \\
\hline $\mathrm{CH}_{2} \mathrm{OH}+\mathrm{H} \rightarrow \mathrm{H}_{2} \mathrm{CO}+\mathrm{H}_{2}$ & $k_{236 b}=1.0 \times 10^{-11}$ \\
\hline $\mathrm{CH}_{2} \mathrm{OH}+{ }^{3} \mathrm{CH}_{2} \rightarrow \mathrm{OH}+\mathrm{C}_{2} \mathrm{H}_{4}$ & $k_{238 a}=4.0 \times 10^{-11}$ \\
\hline $\mathrm{CH}_{2} \mathrm{OH}+\mathrm{CH}_{3} \rightarrow \mathrm{H}_{2} \mathrm{CO}+\mathrm{CH}_{4}$ & $k_{240}=4.0 \times 10^{-12}$ \\
\hline $\mathrm{CH}_{2} \mathrm{OH}+\mathrm{C}_{2} \mathrm{H}_{3} \rightarrow \mathrm{OH}+\mathrm{C} 3 \mathrm{H} 5$ & $k_{243 a}=2.0 \times 10^{-11}$ \\
\hline $\mathrm{CH}_{2} \mathrm{OH}+\mathrm{C}_{2} \mathrm{H}_{3} \rightarrow \mathrm{H}_{2} \mathrm{CO}+\mathrm{C}_{2} \mathrm{H}_{4}$ & $k_{243 b}=5.0 \times 10^{-11}$ \\
\hline $\mathrm{CH}_{2} \mathrm{OH}+\mathrm{C}_{2} \mathrm{H}_{5} \rightarrow \mathrm{CH}_{3} \mathrm{OH}+\mathrm{C}_{2} \mathrm{H}_{4}$ & $k_{245 b}=4.0 \times 10^{-12}$ \\
\hline $\mathrm{CH}_{3} \mathrm{O}+\mathrm{H} \rightarrow \mathrm{OH}+\mathrm{CH}_{3}$ & $k_{249 a}=7.52 \times 10^{-11} \exp (-375.0 / T)$ \\
\hline $\mathrm{CH}_{3} \mathrm{O}+\mathrm{H} \rightarrow \mathrm{H}_{2} \mathrm{CO}+\mathrm{H}_{2}$ & $k_{249 b}=3.38 \times 10^{-11} \exp (-375.0 / T)$ \\
\hline $\mathrm{CH}_{3} \mathrm{O}+{ }^{3} \mathrm{CH}_{2} \rightarrow \mathrm{H}_{2} \mathrm{CO}+\mathrm{CH}_{3}$ & $k_{251}=3.0 \times 10^{-11}$ \\
\hline $\mathrm{CH}_{3} \mathrm{O}+\mathrm{CH}_{3} \rightarrow \mathrm{H}_{2} \mathrm{CO}+\mathrm{CH}_{4}$ & $k_{252}=4.0 \times 10^{-11}$ \\
\hline $\mathrm{CH}_{3} \mathrm{O}+\mathrm{C}_{2} \mathrm{H}_{3} \rightarrow \mathrm{H}_{2} \mathrm{CO}+\mathrm{C}_{2} \mathrm{H}_{4}$ & $k_{255}=4.0 \times 10^{-11}$ \\
\hline $\mathrm{CH}_{3} \mathrm{O}+\mathrm{C}_{2} \mathrm{H}_{5} \rightarrow \mathrm{H}_{2} \mathrm{CO}+\mathrm{C}_{2} \mathrm{H}_{6}$ & $k_{256}=4.0 \times 10^{-11}$ \\
\hline $\mathrm{CH}_{3} \mathrm{O}+\mathrm{CH}_{3} \mathrm{O} \rightarrow \mathrm{H}_{2} \mathrm{CO}+\mathrm{CH}_{3} \mathrm{OH}$ & $k_{258}=1.0 \times 10^{-10}$ \\
\hline $\mathrm{CH}_{3} \mathrm{O}+\mathrm{CH}_{3} \mathrm{CO} \rightarrow \mathrm{CH}_{3} \mathrm{CHO}+\mathrm{H}_{2} \mathrm{CO}$ & $k_{260 b}=1.0 \times 10^{-11}$ \\
\hline $\mathrm{CH}_{3} \mathrm{O}+\mathrm{CH}_{3} \mathrm{CHO} \rightarrow \mathrm{CH}_{3} \mathrm{CO}+\mathrm{CH}_{3} \mathrm{OH}$ & $k_{261}=6.0 \times 10^{-15}$ \\
\hline $\mathrm{CH}_{3} \mathrm{OH}+\mathrm{H} \rightarrow \mathrm{H}_{2} \mathrm{O}+\mathrm{CH}_{3}$ & $k_{262 a}=1.8 \times 10^{-17} T^{2.1} \exp (-2450.0 / T)$ \\
\hline $\mathrm{CH}_{3} \mathrm{OH}+\mathrm{H} \rightarrow \mathrm{CH}_{2} \mathrm{OH}+\mathrm{H}_{2}$ & $k_{262 b}=1.8 \times 10^{-17} T^{2.1} \exp (-2450.0 / T)$ \\
\hline $\mathrm{CH}_{3} \mathrm{OH}+\mathrm{CH}_{3} \rightarrow \mathrm{CH}_{3} \mathrm{O}+\mathrm{CH}_{4}$ & $k_{265 b}=2.39 \times 10^{-23} T^{3.1} \exp (-3490.0 / T)$ \\
\hline $\mathrm{CH}_{3} \mathrm{OH}+\mathrm{C}_{2} \mathrm{H} \rightarrow \mathrm{CH}_{2} \mathrm{OH}+\mathrm{C}_{2} \mathrm{H}_{2}$ & $k_{266 a}=1.0 \times 10^{-11}$ \\
\hline $\mathrm{CH}_{3} \mathrm{OH}+\mathrm{C}_{2} \mathrm{H} \rightarrow \mathrm{CH}_{3} \mathrm{O}+\mathrm{C}_{2} \mathrm{H}_{2}$ & $k_{266 b}=2.0 \times 10^{-12}$ \\
\hline
\end{tabular}


Table A.1. continued.

\begin{tabular}{|c|c|}
\hline Reaction & Rate coefficient \\
\hline $\mathrm{H}_{3} \mathrm{OH}+\mathrm{C}_{2} \mathrm{H}_{3} \rightarrow \mathrm{CH}_{3} \mathrm{O}+\mathrm{C}_{2} \mathrm{H}_{4}$ & $k_{267 b}=2.4 \times 10^{-23} T^{3.1} \exp (-3490.0 / T)$ \\
\hline${ }_{2}+\mathrm{CH} \rightarrow \mathrm{CO}+\mathrm{OH}$ & $k_{269 a}=2.75 \times 10^{-11}$ \\
\hline $\mathrm{O}_{2}+\mathrm{CH} \rightarrow \mathrm{HCO}+\mathrm{O}\left({ }^{3} \mathrm{P}\right)$ & $k_{269 b}=2.75 \times 10^{-11}$ \\
\hline${ }_{2}+{ }^{3} \mathrm{CH}_{2} \rightarrow \mathrm{CO}+\mathrm{OH}+\mathrm{H}$ & $k_{270 a}=1.0 \times 10^{-12}$ \\
\hline $\mathrm{O}_{2}+{ }^{3} \mathrm{CH}_{2} \rightarrow \mathrm{CO}+\mathrm{H}_{2} \mathrm{O}$ & $k_{270 b}=4.0 \times 10^{-13}$ \\
\hline $\mathrm{HCCO}+\mathrm{H} \rightarrow \mathrm{CO}+{ }^{3} \mathrm{CH}_{2}$ & $k_{271}=2.5>$ \\
\hline $\mathrm{H}_{2} \mathrm{CO}+\mathrm{H} \rightarrow \mathrm{CO}+\mathrm{CH}_{3}$ & $k_{272}=3.0 \times 10^{-11} \exp (-17$ \\
\hline $\mathrm{H}_{2} \mathrm{CO}+{ }^{3} \mathrm{CH}_{2} \rightarrow \mathrm{CO}+\mathrm{C}_{2} \mathrm{H}_{4}$ & $k_{273 a}=2.1 \times 10^{-10}$ \\
\hline $\mathrm{H}_{2} \mathrm{CO}+{ }^{3} \mathrm{CH}_{2} \rightarrow \mathrm{HCCO}+\mathrm{CH}_{3}$ & $k_{273 b}=1.0 \times 10^{-17}$ \\
\hline $\mathrm{H}_{3} \mathrm{CO}+\mathrm{H} \rightarrow \mathrm{HCO}+\mathrm{CH}_{3}$ & $k_{274 a}=3$. \\
\hline $\mathrm{H}_{3} \mathrm{CO}+\mathrm{H} \rightarrow \mathrm{CH}_{2} \mathrm{CO}+\mathrm{H}_{2}$ & $k_{274 b}=1.92 \times 1$ \\
\hline $\mathrm{H}_{3} \mathrm{CO}+{ }^{3} \mathrm{CH}_{2} \rightarrow \mathrm{CH}_{2} \mathrm{CO}+\mathrm{CH}_{3}$ & $k_{275}=3.0 \times 10^{-11}$ \\
\hline $\mathrm{H}_{3} \mathrm{CO}+\mathrm{CH}_{3} \rightarrow \mathrm{CO}+\mathrm{C}_{2} \mathrm{H}_{6}$ & $k_{276 a}=4.9 \times 10^{-11}$ \\
\hline $\mathrm{H}_{3} \mathrm{CO}+\mathrm{CH}_{3} \rightarrow \mathrm{CH}_{2} \mathrm{CO}+\mathrm{CH}_{4}$ & $k_{276 b}=1.0 \times 10^{-11}$ \\
\hline $\mathrm{H}_{3} \mathrm{CO}+\mathrm{C}_{2} \mathrm{H} \rightarrow \mathrm{CH}_{2} \mathrm{CO}+\mathrm{C}_{2} \mathrm{H}_{2}$ & $k_{277}=3.0 \times 10^{-11}$ \\
\hline $\mathrm{H}_{3} \mathrm{CHO}+\mathrm{H} \rightarrow \mathrm{CH}_{3} \mathrm{CO}+\mathrm{H}_{2}$ & $k_{279}=2.23 \times 10^{-11} \exp (-1$ \\
\hline $\mathrm{H}_{3} \mathrm{CHO}+{ }^{3} \mathrm{CH}_{2} \rightarrow \mathrm{CH}_{3} \mathrm{CO}+\mathrm{CH}_{3}$ & $k_{280}=2.76 \times 10^{-12} \exp (-1768.0 / T)$ \\
\hline $\mathrm{H}_{3} \mathrm{CHO}+\mathrm{CH}_{3} \rightarrow \mathrm{CH}_{3} \mathrm{CO}+\mathrm{CH}_{4}$ & $3 \times 10^{-30} T^{5.64} \exp (-1240.0 / T)$ \\
\hline $\mathrm{O}_{2}+\mathrm{CH} \rightarrow \mathrm{HCO}+\mathrm{CO}$ & $k_{284}=5.7 \times 10^{-12} \exp (-345.0 / T)$ \\
\hline $\mathrm{CO}_{2}+{ }^{3} \mathrm{CH}_{2} \rightarrow \mathrm{CO}+\mathrm{H}_{2} \mathrm{CO}$ & $k_{285}=3.9 \times 10^{-14}$ \\
\hline $\mathrm{C}_{2} \mathrm{H}_{4} \mathrm{OH}+\mathrm{H} \rightarrow \mathrm{CH}_{3} \mathrm{CHO}+\mathrm{H}_{2}$ & $k_{286}=8.3 \times 10^{-11}$ \\
\hline $\mathrm{C}_{2} \mathrm{H}_{4} \mathrm{OH}+\mathrm{CH}_{3} \rightarrow \mathrm{CH}_{3} \mathrm{CHO}+\mathrm{C}$ & $k_{287}=4$ \\
\hline
\end{tabular}

